\title{
Evolution of an interaction between disordered proteins resulted in increased heterogeneity of the binding transition state
}

Elin Karlsson ${ }^{1}$, Cristina Paissoni ${ }^{2}$, Amanda M. Erkelens ${ }^{1,3}$, Zeinab Amiri Tehranizadeh ${ }^{1,4}$, Frieda A. Sorgenfrei ${ }^{1,5}$, Eva Andersson ${ }^{1}$, Weihua Ye $^{1}$, Carlo Camilloni $^{2, *}$, and Per Jemth ${ }^{1, *}$

${ }^{1}$ Department of Medical Biochemistry and Microbiology, Uppsala University, BMC Box 582, SE-75123 Uppsala, Sweden.

${ }^{2}$ Dipartimento di Bioscienze, Università degli Studi di Milano, 20133 Milano, Italy.

${ }^{3}$ Present address: Department of Chemistry, Leiden University, Leiden, Netherlands.

${ }^{4}$ Department of Medicinal Chemistry, School of Pharmacy, Mashhad University of Medical Sciences, Mashhad, Iran.

${ }^{5}$ Present address: Department of Chemistry, Institute of Organic and Bioorganic Chemistry, University of Graz, Heinrichstraße 28, 8010 Graz, Austria.

*Correspondence to:

Per Jemth, Per.Jemth@imbim.uu.se, phone: +46-18-471 4557

Carlo Camilloni, carlo.camilloni@unimi.it, phone:+39-02-503 14918 


\begin{abstract}
Intrinsically disordered protein (IDP) domains often have multiple binding partners. Little is known regarding molecular changes in the binding mechanism when a new interaction evolves from low to high affinity. Here we compared the degree of native contacts in the transition state of the interaction of two IDP domains, low-affinity ancestral and high-affinity human NCBD and CID. We found that the coupled binding and folding mechanism of the domains is overall similar, but with a higher degree of native hydrophobic contact formation in the transition state of the ancestral complex while more heterogenous transient interactions, including electrostatic, and an increased disorder characterize the human complex. From an evolutionary perspective, adaptation to new binding partners for IDPs may benefit from this ability to exploit multiple alternative transient interactions while retaining the overall pathway.
\end{abstract}




\section{Introduction}

Intrinsically disordered proteins (IDPs) are abundant in the human proteome ${ }^{1}$ and are frequently involved in mediating protein-protein interactions in the cell. The functional advantages of disordered proteins include exposure of linear motifs for association with other proteins, accessibility for post-translational modifications, formation of large binding interfaces and the ability to interact specifically with multiple partners. These properties make IDPs suitable for regulatory functions in the cell, wherefore IDPs often act as hubs in interaction networks governing signal transduction pathways and transcriptional regulation ${ }^{2}$.

Despite recent appreciation of the biological importance of IDPs and progress in understanding their mechanism of interaction with other proteins, the changes that take place at a molecular level when these proteins evolve to bind new binding partners remain elusive. The reason for this is the inherent difficulty in assessing effects of mutations that a protein has acquired during millions or billions of years. However, the rapidly increasing number of available protein sequences from extant species has enabled the development of ancestral sequence reconstruction as a tool for inferring the evolutionary history of proteins ${ }^{3}$. Ancestral sequence reconstruction relies on an alignment of sequences from extant species and a maximum likelihood method that infers probabilities for amino acids at each position in the reconstructed ancestral protein from a common ancestor. However, due to less constraints for maintaining a folded structure, IDPs in general experience faster amino acid substitution rates during evolution and an increased occurrence of amino acid deletion and insertion events as compared to folded proteins, which often obstructs reliable sequence alignments of IDPs ${ }^{4-6}$. Nevertheless, IDP regions that form binding interfaces in coupled binding and folding interactions are usually conserved because of sequence restraints for maintaining affinity and 
structure of the protein complex ${ }^{7}$, and can therefore be subjected to ancestral sequence reconstruction. The ability to mutate while maintaining certain sequence characteristics might allow IDPs to more efficiently explore sequence space, facilitating adaptation to new binding partners.

The nuclear co-activator binding domain (NCBD) from CREB-binding protein (CBP) is engaged in multiple protein-protein interactions in the cell ${ }^{8}$. NCBD is a molten globule-like protein $^{9}$, which forms three helices in the unbound state that rearranges upon binding to its different partners ${ }^{10-12}$. These binding partners include among others the transcription factors and transcriptional co-regulators p53, IRF3 and NCOA1, 2 and 3 (also called SRC, TIF2 and ACTR, respectively). The interaction between NCBD and the CBP-interacting domain (CID) from NCOA3 (ACTR) has been intensively studied with kinetic methods to elucidate details about the binding mechanism ${ }^{13-16}$. These protein domains interact in a coupled folding and binding reaction in which CID forms two to three helices that wrap around $\mathrm{NCBD}^{10}$. The binding reaction involves several steps, as evidenced from the multiple kinetic phases observed in stopped flow spectroscopy and single molecule-FRET experiments ${ }^{16-18}$. It is however not clear what all kinetic phases corresponds to and equilibrium data agree well with the major kinetic binding phase ${ }^{19}$ in overall agreement with a two-state binding mechanism.

Previous phylogenetic analyses revealed that while NCBD was present already in the last common ancestor of all bilaterian animals (deuterostomes and protostomes) CID likely emerged later as an interaction domain within the ancestral ACTR/TIF2/SRC protein in the deuterostome lineage (including chordates, echinoderms and hemichordates; Figure 1$)^{20}$. The evolution of the NCBD/CID interaction was previously examined using ancestral sequence reconstruction in combination with several biophysical methods to assess differences in 
affinity, structure and dynamics between the extant human and ancestral protein complex ${ }^{20,21}$. After the emergence of CID in the ancestral ACTR/TIF2/SRC, NCBD increased its affinity for CID while maintaining the affinity for some of its other binding partners ${ }^{20}$. While the overall structure of the ancestral NCBD/CID complex, which we denote as "Cambrian-like", is similar to the modern high affinity human one, there are several differences on the molecular level (Figure 1) ${ }^{21}$.

Here, we address the molecular details of the evolutionary optimization of the interaction between NCBD and CID. In order to investigate how evolution has modulated the binding energy landscape of this interaction, and in particular its transition state, we subjected the Cambrian-like NCBD/CID complex to site-directed mutagenesis and kinetic measurements using fluorescence-monitored stopped flow spectroscopy. The Cambrian-like complex consisted of the maximum likelihood estimate (ML) NCBD variant from the time of the divergence between deuterostomes and protostomes, $\mathrm{NCBD}_{\mathrm{D} / \mathrm{P}}^{\mathrm{ML}}$, and the $\mathrm{CID}$ variant from the time of the first whole genome duplication, $\mathrm{CID}_{1 \mathrm{R}}{ }^{\mathrm{ML}}$. The experimental data were used to estimate the degree of native intermolecular tertiary contacts as well as helical content of CID in the transition state, expressed as phi $(\phi)$-values. The $\phi$-value, which commonly ranges from 0 to 1 , reports on formation of native contacts in the transition state and was originally developed for folding studies ${ }^{22}$, however, it has also been used to gain detailed information about the transition state structures for several IDP binding reactions ${ }^{23}$. Furthermore, to obtain an atomic-level detail of the binding and folding process, the $\phi$-values were employed for restrained molecular dynamics (MD) simulations. Our results suggest that while the overall binding mechanism and transition state are conserved, some modulation of helical content in the transition state and, most notably, an increased heterogeneity of transient intermolecular 
bioRxiv preprint doi: https://doi.org/10.1101/2020.03.27.012328; this version posted March 29, 2020. The copyright holder for this preprint (which was not certified by peer review) is the author/funder, who has granted bioRxiv a license to display the preprint in perpetuity. It is made available under aCC-BY-NC-ND 4.0 International license.

interactions is observed between the low-affinity Cambrian-like and high-affinity modern human complexes. 


\section{Results}

\section{Experimental strategy}

We have characterized the transition state of binding for the low-affinity Cambrian-like NCBD/CID complex in terms of $\phi$-values and compared it to that of the high-affinity modern human complex. A $\phi$-value can be employed as a region-specific probe for native contact formation in the transition state of a binding reaction. A $\phi$-value of 0 means that the entire effect on $K_{D}$ from the mutation stems from a change in $k_{\text {off }}$, indicating that the interactions with the mutated residue mainly forms after the transition state barrier of binding. On the other hand, a $\phi$-value of 1 is obtained when the effect of mutation on $k_{o n}$ and $K_{D}$ is equally large, which suggests that the mutated residue is making fully formed native contacts at the top of the transition state barrier. To characterize the transition state for binding, we performed extensive site-directed mutagenesis in the Cambrian-like complex and subjected each mutant to stopped-flow kinetic experiments to obtain binding rate constants (i.e., $k_{o n}$ and $k_{\text {off }}$ (Figure $1 \mathrm{c}$ ). These rate constants were used to compute $\phi$-values for each mutated position in the complex (Figure 2 a). To provide more structural details about the evolution of the NCBD/CID interaction, we also determined the TS ensemble of the Cambrian-like complex via $\phi$-value-restrained MD simulations, following the same procedure previously used to obtain the TS ensemble of the human complex ${ }^{24}$.

In the present study we used $\mathrm{NCBD}_{\mathrm{D} / \mathrm{P}}^{\mathrm{T} 2073 \mathrm{~W}}$ as a pseudo wild type (Figure $1 \mathrm{e}$; denoted

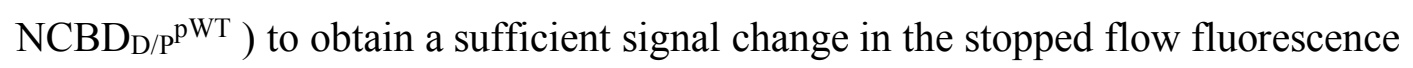
measurements. While Trp pseudo wild types have been shown to be reliable in protein folding studies $^{25}$ it is less clear how much an engineered Trp would affect an IDP complex in a coupled binding and folding reaction. Therefore, we initially tested five different Trp mutants of $\mathrm{NCBD}_{\mathrm{D} / \mathrm{P}} \mathrm{ML}$ to select the one with properties most similar to $\mathrm{NCBD}_{\mathrm{D} / \mathrm{P}} \mathrm{ML}$ (Fig. S1). To 
check how robust our $\phi$-values were to the position of the Trp probe we measured five $\phi$ values with one of the other Trp variants, $\mathrm{NCBD}_{\mathrm{D} / \mathrm{P}} \mathrm{L} 2067 \mathrm{~W}$. Despite a two-fold lower $k_{\mathrm{on}}$ as compared to $\mathrm{NCBD}_{\mathrm{D} / \mathrm{P}^{\mathrm{pWT}}}$ (i.e., $\mathrm{NCBD}_{\mathrm{D} / \mathrm{P}^{\mathrm{T}} 2073 \mathrm{~W}}$ ) all five values were very similar, including the negative $\phi$-value obtained for D1068A (Table 3), suggesting that our $\phi$-values are robust and not dependent on the optical probe.

We constructed two sets of mutants in this study to characterize the transition state for binding: one that targeted native contacts in the binding interface and a second that targeted native helices in CID. The first set consisted of $13 \mathrm{NCBD}_{\mathrm{D} / \mathrm{P}^{\mathrm{pWT}}}$ variants and $10 \mathrm{CID}_{1 \mathrm{R}}^{\mathrm{ML}}$ variants mainly corresponding to previously mutated residues in the human complex ${ }^{13,26}$. The positions spanned the entire binding interface of NCBD and CID to ensure that all regions of the protein domains were probed (Table 1). The majority of the mutations targeted interactions between hydrophobic residues in the binding interface, however, a few mutations also probed interactions between charged residues. The second set of mutants consisted of $\mathrm{Ala} \rightarrow$ Gly substitutions in helix 1 and 2 of $\mathrm{CID}_{1 \mathrm{R}}^{\mathrm{ML}}$, as well as helix 2 and 3 of $\mathrm{CID}_{\text {Human }}$ complementing a previous data set for helix-modulating mutations in helix 1 of $\mathrm{CID}_{\mathrm{Human}}{ }^{27}$. The secondary structure content of all mutants was assessed with far-UV CD. All CID variants exhibited far-UV CD spectra typical for highly disordered proteins (Figure S2 a-b). For NCBD, the far-UV CD measurements showed that $\mathrm{NCBD}_{\mathrm{D} / \mathrm{P}}{ }^{\mathrm{L} 2070 \mathrm{~A}}, \mathrm{NCBD}_{\mathrm{D} / \mathrm{P}}{ }^{\mathrm{L} 2090 \mathrm{~A}}$, $\mathrm{NCBD}_{\mathrm{D} / \mathrm{P}}{ }^{\mathrm{L} 2096 \mathrm{~A}}$ and $\mathrm{NCBD}_{\mathrm{D} / \mathrm{P}^{\mathrm{A} 2099 \mathrm{G}}}$ displayed substantially less $\alpha$-helical structure than $\mathrm{NCBD}_{\mathrm{D} / \mathrm{P}} \mathrm{pWT}$, as judged from the lower magnitude of the CD signal at $222 \mathrm{~nm}$ (Figure $\mathrm{S} 2 \mathrm{c}$ ). Addition of $0.7 \mathrm{M}$ trimethylamine N-oxide (TMAO) to the experimental buffer for these variants resulted in an increase in helical content such that the far-UV CD spectra of $\mathrm{NCBD}_{\mathrm{D} / \mathrm{P}}^{\mathrm{L} 2070 \mathrm{~A}}$ and $\mathrm{NCBD}_{\mathrm{D} / \mathrm{P}^{\mathrm{L} 2096 \mathrm{~A}}}$ were qualitatively similar to $\mathrm{NCBD}_{\mathrm{D} / \mathrm{P}^{\mathrm{pWT}}}$ (Figure $\mathrm{S} 2 \mathrm{~d}$ ). For $\mathrm{NCBD}_{\mathrm{D} / \mathrm{P}} \mathrm{L}^{\mathrm{L} 2096 \mathrm{~A}}$ and $\mathrm{NCBD} \mathrm{D} / \mathrm{P}^{\mathrm{A} 2099 \mathrm{G}}$ stopped-flow kinetic experiments were carried out 
both in regular buffer and in buffer supplemented with 0.7 M TMAO. The resulting $\phi$-values were very similar for these variants at both conditions (Figure S4). The complex of the $\mathrm{NCBD}_{\mathrm{D} / \mathrm{P}} \mathrm{L}^{\mathrm{L} 2070 \mathrm{~A}}$ variant was too unstable in buffer and data was only recorded in presence of 0.7 M TMAO. Several mutants failed to generate kinetic data due to elevated $k_{o b s}$ values, which were too high to be reliably recorded with the stopped-flow technique. This was the

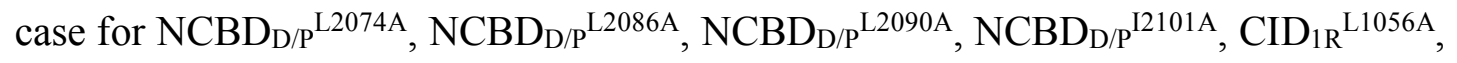
$\mathrm{CID}_{1 \mathrm{R}}{ }^{\mathrm{L} 1064 \mathrm{~A}}, \mathrm{CID}_{1 \mathrm{R}}{ }^{\mathrm{I1067A}}$ and $\mathrm{CID}_{1 \mathrm{R}}^{\mathrm{L} 1071 \mathrm{~A}}$.

\section{HSQC spectra suggest that the structure of the complex is robust to mutation.}

One caveat with $\phi$-value analysis is the assumption that ground states are not affected by mutation. Hence, the strategy of using conservative deletion mutations is important ${ }^{28}$. For example, mutation to a larger residue is not considered conservative and one of the Trp variants that we tested, $\mathrm{NCBD}_{\mathrm{D} / \mathrm{P}} \mathrm{S} 2078 \mathrm{~W}$, displayed a very low $k_{\mathrm{on}}\left(3.5 \mu \mathrm{M}^{-1} \mathrm{~s}^{-1}\right)$ and a 2 -fold lower $k_{\text {off }}$ than the other NCBD variants (Fig. S1). We can only speculate about the structural basis for this result but since the residue is situated in the loop between $\mathrm{N} \alpha 1$ and $\mathrm{N} \alpha 2$ it might either lock the two helices in relation to each other or flip over, cover the binding groove and thus block access for CID. In either case we have a clear effect on the ground state. The problem of ground state changes may be particularly pertaining for IDPs, since they are more malleable in terms of structural changes to accommodate binding partners. It is beyond the scope of this study to perform extensive structure determination of all site-directed mutants but we recorded HSQC spectra for one complex containing a typical deletion mutation and an intermediate $\phi$-value, $\mathrm{NCBD}_{\mathrm{D} / \mathrm{P}}^{\mathrm{L} 2067 \mathrm{~A}}$ with $\mathrm{CID}_{1 \mathrm{R}}^{\mathrm{ML}}$ (Fig. S3 a-b). The similar distribution of peaks, in particular for $\mathrm{CID}_{1 \mathrm{R}}{ }^{\mathrm{ML}}$, suggests that the structure of the complex between $\mathrm{CID}_{1 \mathrm{R}} \mathrm{ML}$

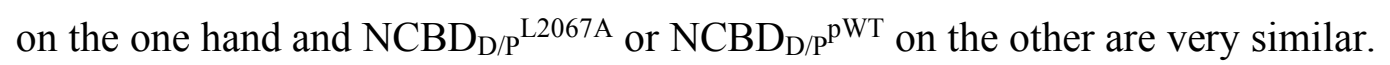




\section{The transition state of the Cambrian-like complex is more native-like than the extant}

\section{human complex.}

First, we assessed interactions formed by hydrophobic side chains in the binding interface of the ancestral Cambrian-like complex by computing $\phi$-values for each mutant (Table 1). The resulting $\phi$-values were mainly in the intermediate category ranging between 0.3-0.6 (Figure 2 a). This result was in contrast with previously published low $\phi$-values for the human complex $^{29}$, which ranged between $0-0.3$ for similar conservative deletion mutations (Figure 2 b). A notable exception was the $\mathrm{CID}_{\mathrm{Human}}{ }^{\mathrm{L} 1055 \mathrm{~A}}$ variant, which displayed a $\phi$-value of 0.83 . This residue is located in the first $\alpha$-helix, which is transiently populated in the free state of CID and forms many native contacts with NCBD in the transition state ${ }^{26,30}$. The $\mathrm{CID}_{1 \mathrm{R}}{ }^{\mathrm{L} 1055 \mathrm{~A}}$ in the Cambrian-like complex displayed a similarly high $\phi$-value $(0.83)$, suggesting that this region forms a conserved nucleus for the coupled binding and folding of CID/NCBD. Further comparison between $\phi$-values in the Cambrian-like and human complex at a site-by-site basis shows that three mutations in particular, $\mathrm{NCBD}^{\mathrm{L} 2067 \mathrm{~A}}, \mathrm{NCBD}^{\mathrm{L} 2087 \mathrm{~A}}$ and $\mathrm{NCBD}^{\mathrm{L} 2096 \mathrm{~A}}$, displayed large differences in $\phi$-values in the respective complex, with the Cambrian-like complex always showing higher $\phi$-values. The differences suggest rearrangements of native contacts in the transition states from a low-affinity, more native-like, Cambrian-like complex to a high-affinity, more disordered, human complex (Figure $2 \mathrm{c}$ ).

Accordingly, MD simulations showed that the Cambrian-like TS, as compared to the human one, is significantly more compact (as judged by gyration radius, Figure 3e) and less heterogeneous (as judged by pairwise RMSD, Figure 3d), supporting the idea that the TS for formation of the Cambrian-like complex is more native-like. The higher NCBD $\phi$-values (Table S1 and Figure 2c) measured for the ancestral complex resulted in differences in both the NCBD secondary/tertiary structure and the intermolecular interactions in the TS. In the 
ancestral TS, the NCBD helix Na3 is totally unfolded (consistent with its lower helicity also in the native state) $)^{31}$, while helices $\mathrm{N} \alpha 1$ and $\mathrm{N} \alpha 2$ are well formed and maintain a native-like relative orientation with numerous $\mathrm{N} \alpha 1-\mathrm{N} \alpha 2$ contacts (Figure $3 \mathrm{c}$ and $3 \mathrm{~b}$, box 1 ). On the other hand, in the human TS, N 1 and $\mathrm{N} \alpha 2$ show lower helical content and contacts are less frequent. The main intermolecular contacts are conserved in human and Cambrian-like TS: in both the cases we observed a stable hydrophobic core (Figure 3b, boxes 2), involving C $\alpha 1$ (via residues Leu1052 and Leu1055, which displays high $\phi$-value in both complexes) and Na1 (via residues Leu2071, Leu2074 and Lys2075), but with a slightly different orientation of the two helices. A second relevant interacting region involves the residues of the unstructured CID helices C $\alpha 2-\mathrm{C} \alpha 3$, which contact NCBD in both TS ensembles. In the ancestral complex, hydrophobic residues of $\mathrm{N} \alpha 2$ helix are preferred, while in the human TS the interactions are more dispersed, involving also the longer and structured helix $\mathrm{N} \alpha 3$ (Figure 3b, box 3). The identified interactions are highly native-like in the case of the ancestral complex (Figure S5) as compared to the human one ${ }^{24}$, where a higher number of transient contacts is observed (Figure S6). These observations agree with a Brønsted plot analysis where $\Delta \Delta \mathrm{G}_{\mathrm{TS}}$ is plotted versus $\Delta \Delta \mathrm{G}_{\mathrm{EQ}}$. A salient feature of a nucleation-condensation mechanism in protein folding, where all non-covalent interactions form cooperatively, is a clear linear dependence of the Brønsted plot. In the case of hydrophobic mutations in Cambrian-like NCBD/CID, the Brønsted plot appeared rather scattered as compared to human NCBD/CID (Fig. 2d) and previously characterized IDP systems. One reason for this could be the relatively narrow range of $\Delta \Delta \mathrm{G}_{\mathrm{EQ}}$ values that can be obtained for the less stable Cambrian-like complex as compared to human NCBD/CID. Nevertheless, the scatter is consistent with the larger spread of values in the Brønsted plot for Cambrian-like NCBD/CID and a less cooperative disorder-to-order transition of Cambrian-like as compared to human NCBD/CID. 


\section{The mechanism of helix formation in CID has been well-conserved during evolution.}

The binding reaction of NCBD and CID is associated with a dramatic increase in secondary structure content of CID. Helical propensity of the N-terminal helix of CID correlates positively with affinity for $\mathrm{NCBD}^{27}$ and modulation of helical propensity is likely an important evolutionary mechanism for tuning affinities of interactions involving IDPs. To investigate native helix formation in the transition state of the Cambrian-like complex, we introduced Ala $\rightarrow$ Gly mutations at surface exposed positions in helix 1 of $\mathrm{CID}_{1 \mathrm{R}}^{\mathrm{ML}}\left(\mathrm{C} \alpha 1_{1 \mathrm{R}}\right)$ and in helix $2\left(\mathrm{C} \alpha 2_{1 \mathrm{R}}\right)$. The mutants were subjected to binding experiments and the rate constants were used to compute $\phi$-values for each CID variant in complex with $\mathrm{NCBD}_{\mathrm{D} / \mathrm{P}^{\mathrm{pWT}}}$ (Table 1). The $\phi$-values for C $\alpha 1_{1 \mathrm{R}}$ were ranging between $0.2-0.3$ and were lower, close to 0.1 , for $\mathrm{C} \alpha 2_{1 \mathrm{R}}$ (Figure $4 \mathrm{a}$ ). Brønsted plots resulted in slopes for $\mathrm{C} \alpha 1_{1 \mathrm{R}}$ and $\mathrm{C} \alpha 2_{1 \mathrm{R}}$ of 0.3 and 0 , respectively (Figure $4 \mathrm{~b}$ ). The slope of the Brønsted plot can be regarded as an average $\phi$ value and thus suggests around $30 \%$ and $0 \%$ native helical content of $C \alpha 1_{1 \mathrm{R}}$ and $\mathrm{C} \alpha 2_{1 \mathrm{R}}$, respectively, in the transition state for the Cambrian-like complex.

To facilitate a direct comparison with the extant human complex, we extended a previously published data set on helix 1 from human CID $\left(\mathrm{C} \alpha 1_{\text {Human }}\right)^{27}$ with new Ala $\rightarrow$ Gly mutations in helix 2 (C $\left.\alpha 2_{\text {Human }}\right)$ and helix $3\left(\mathrm{C} \alpha 3_{\text {Human }}\right)$ (Table 2). The human complex displayed $\phi$-values for helix formation in $\mathrm{C} \alpha 1_{\text {Human }}$ that ranged from $0.3-0.7$, whereas all $\phi$-values in $\mathrm{C} \alpha 2_{\mathrm{Human}}$

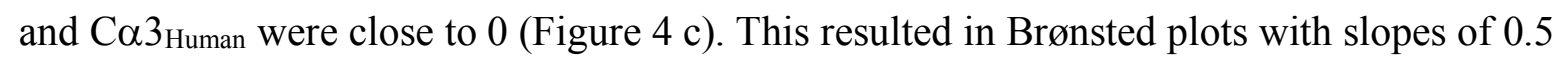
for $\mathrm{C} \alpha 1_{\mathrm{Human}}{ }^{27}$ and virtually 0 for $\mathrm{C} \alpha 2_{\mathrm{Human}} \mathrm{C} \alpha 3_{\mathrm{Human}}$ (Figure $4 \mathrm{~d}$ ). Thus, in both the Cambrian-like and human complexes, the $\mathrm{N}$-terminal $\mathrm{C} \alpha 1$ plays an important role in forming early intramolecular native secondary structure contacts in the disorder-to-order transition. 
These data are well represented by the ancestral TS ensemble. The probability of $\alpha$-helix content in CID, measured via $\operatorname{DSSP}^{32}$ and averaged over the whole ensemble, shows that only helix $\mathrm{C} \alpha 1$ is partially formed in the TS, while other CID helices are mostly unstructured (Figure 3c). Analogously, in the TS of the human complex only helix C $\alpha 1$ was folded, overall supporting the importance of Cal formation for NCBD binding.

We note that according to Brønsted plots, $\mathrm{C} \alpha 1_{\text {Human }}$ has a slightly higher helical content in the transition state compared to $\mathrm{C} \alpha 1_{1 \mathrm{R}}$, consistent with a higher helical propensity for $\mathrm{C} \alpha 1_{\mathrm{Human}}$ than for $\mathrm{C} \alpha 1_{1 \mathrm{R}}$, as suggested by predictions using $\mathrm{AGADIR}^{20}$. We further note that the A1075G mutation in $\mathrm{C} \alpha 3_{\text {Human }}$ did not display a large effect on $K_{D}$, which precluded a reliable estimation of a $\phi$-value. This could indicate either that $\mathrm{C} \alpha 3_{\text {Human }}$ contributes little to the stability of the bound complex or that the Ala $\rightarrow$ Gly substitution at this position promotes an alternative conformation that binds with equal affinity as the wildtype protein. Similarly, Val1077 $\rightarrow$ Ala in $\mathrm{C} \alpha 3_{\text {Human }}$ was shown previously to have a small positive effect on the affinity for $\mathrm{NCBD}^{29}$, suggesting structural re-arrangement in the bound state.

\section{Role of a conserved and buried salt-bridge in the Cambrian-like complex.}

Long-range electrostatic interactions promote association of proteins and play a major role in IDPs. Mutation of a conserved salt-bridge between Arg2104 in NCBD and Asp1068 in CID was previously shown to display large effects on the kinetics of complex formation for human $\mathrm{NCBD} / \mathrm{CID}$, both in terms of a 10 -fold reduction in $k_{\text {on }}$ but also with the occurrence of a new kinetic phase $\left(k_{o b s} \approx 15-20 \mathrm{~s}^{-1}\right)$. Analysis of the kinetic data favored an induced fit model, thus a conformational change after binding ${ }^{16,33,34}$. We generated the protein variants $\mathrm{NCBD}_{\mathrm{D} / \mathrm{P}}^{\mathrm{R} 2104 \mathrm{M}}$ and $\mathrm{CID}_{1 \mathrm{R}}{ }^{\mathrm{D} 1068 \mathrm{~A}}$ to assess the role of this salt-bridge in the ancestral Cambrian-like complex. 
$\mathrm{NCBD}_{\mathrm{D} / \mathrm{P}}{ }^{\mathrm{R} 2104 \mathrm{M}}$ and $\mathrm{CID}_{1 \mathrm{R}}{ }^{\mathrm{D} 1068 \mathrm{~A}}$ displayed clear biphasic kinetic traces in the stopped flow experiments, similarly to experiments with the corresponding mutants in the human complex. Fitting of the kinetic data to obtain $k_{o b s}$ values revealed one concentration-dependent kinetic phase, which increased linearly with CID concentration and a second kinetic phase which was constant at $k_{o b s} \approx 16 \mathrm{~s}^{-1}$ over the entire concentration range. Thus, the kinetic data set for the complex between $\mathrm{NCBD}_{\mathrm{D} / \mathrm{P}} \mathrm{R}^{\mathrm{R} 2104 \mathrm{M} / \mathrm{CID}_{1 \mathrm{R}}}{ }^{\mathrm{D} 1068 \mathrm{~A}}$ was fitted globally to an induced fit mechanism to obtain estimates of the microscopic rate constants. The comparison between the Cambrian-like and human complex revealed that the effect of mutating the buried salt-bridge was much smaller with regard to the association rate constant $k_{l}$ for the Cambrian-like complex than for the human complex, less than 2 -fold versus 20 -fold, respectively. On the other hand, the slow phase was similar for both the human and ancestral complex with a $k_{\text {obs }}$ $\left(=k_{2}+k_{-2}\right)$ of $15-20 \mathrm{~s}^{-1}$. However, global fitting suggested that the alternative conformation of the bound state is only slightly populated for the Cambrian-like complex $\left(k_{-2}>>k_{2}\right)$. This was corroborated by ITC measurements, which showed that the overall $K_{D}(5.1 \pm 0.3 \mu \mathrm{M})$ is highly consistent with $k_{-1} / k_{1}(4.8 \mu \mathrm{M})$. Interestingly, while the salt-bridge is significantly populated in the native state simulations, it is not populated in neither the Cambrian-like nor the human TS ensemble, suggesting that the formation of this interaction is not relevant for the initial recognition. Nonetheless these residues promote the association of the human complex most likely via unspecific long-range interactions.

Furthermore, we mutated Asp1053 in $\mathrm{CID}_{1 \mathrm{R}}{ }^{\mathrm{ML}}$ to Ala, to assess potential salt-bridge formation between this residue and $\operatorname{Arg} 2104$ in $\mathrm{NCBD}_{\mathrm{D} / \mathrm{P}} \mathrm{ML}$. The complex between $\mathrm{NCBD}_{\mathrm{D} / \mathrm{P}}^{\mathrm{R} 2104 \mathrm{M}}$ and $\mathrm{CID}_{1 \mathrm{R}}{ }^{\mathrm{D} 1053 \mathrm{~A}}$ was very destabilized and the kinetic phase that reported on the binding event was too fast for the stopped-flow instrument. However, the concentration- 
independent kinetic phase was detected $\left(k_{o b s} \approx 20-40 \mathrm{~s}^{-1}\right)$. Single charge mutations cannot be considered conservative since they may result in unpaired charges in or close to hydrophobic interfaces. Any effects from such mutations may also be due to non-specific charge-charge attraction or repulsion. (The overall charge of $\mathrm{NCBD}_{\mathrm{D} / \mathrm{P}}$ is positive and $\mathrm{CID}_{1 \mathrm{R}}$ is negative.) Nevertheless, we report kinetic data for such single mutants. Interestingly, $\mathrm{CID}_{1 \mathrm{R}}{ }^{\mathrm{D} 1068 \mathrm{~A}}$ displayed a negative $\phi$-value (ca. -0.4, Table 1 and Table 3 ) due to an increase in both $k_{\text {on }}$ and $k_{\text {off }}$ upon mutation, suggesting that Asp1068 makes a non-favorable interaction in the

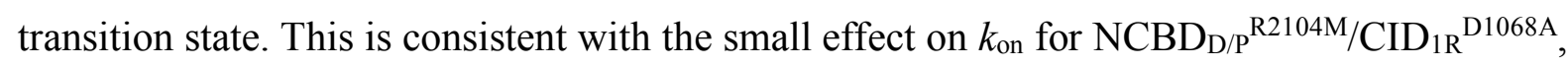
which might result from opposing effects on $k_{\text {on }}$ by the respective mutation. The other Asp mutant, $\mathrm{CID}_{1 \mathrm{R}}{ }^{\mathrm{D} 1053 \mathrm{~A}}$, also displayed an increase in $k_{\text {on }}$ but a positive high $\phi$-value. Thus, Asp1053 forms non-favorable interactions both in the transition state and in the native state of the complex. The $\mathrm{NCBD}_{\mathrm{D} / \mathrm{P}}^{\mathrm{K} 2075 \mathrm{M}}$ variant gives a high $\phi$-value suggesting a native interaction in the transition state. While Asp1053 is in the vicinity of Lys2075 the coupling free energy between them is low $(0.17 \mathrm{kcal} / \mathrm{mol})$ and it is not clear what interactions these residues make in the native complex. All surface charge mutations had little effect on kinetics or yielded low $\phi$-values suggesting that overall charge plays a minor role in the association of $\mathrm{NCBD}_{\mathrm{D} / \mathrm{P}}$ and $\mathrm{CID}_{1 \mathrm{R}}$ (Table 1) and similarly for human NCBD/CID (Table 2).

In agreement with these data, simulations supported the idea that hydrophobic interactions are more relevant than electrostatic contacts in the TS for formation of the ancestral complex. In fact, no stable salt-bridges or hydrogen bonds were observed, with Arg2104 contacting different polar residues only in a transient manner. Also, the high $\phi$-value of the $\mathrm{NCBD}_{\mathrm{D} / \mathrm{P}}{ }^{\mathrm{K} 2075 \mathrm{M}}$ variant can be explained by the ability of Lys2075 to engage in hydrophobic, rather than polar, interactions stabilizing the native-like hydrophobic core formed by helices Ca1-Na1 (Figures 3b and S5). 


\section{Discussion}

The higher prevalence of IDPs among eukaryotes as compared to prokaryotes suggests that these proteins have played an important role in the evolution of complex multicellular $\operatorname{organisms}^{35,36}$. IDPs often participate in regulatory functions in the cell, by engaging in complex interaction networks that fine-tune cellular responses to environmental cues ${ }^{37}$. One feature common to many IDPs, and which has likely contributed to their abundance in regulatory functions, is the ability to interact specifically with several partners that are competing for binding ${ }^{38}$. NCBD is an archetype example of such a disordered protein interaction domain that has evolved to bind several cellular targets, including transcription factors and transcriptional co-regulators ${ }^{10,11,39}$. Every time a new partner was included in the repertoire, NCBD somehow adapted its affinity for the new ligand, while maintaining affinity for already established one(s), as occurred around 450-500 Myr, when the interaction between NCBD and CID was established ${ }^{20}$. On a molecular level, it is intriguing how such multi partner protein domains evolve. In the present study, we have extended our structural studies $^{31}$ and investigated the evolution of the binding mechanism using site-directed mutagenesis, $\phi$-value analysis and restrained MD simulations to shed light on changes occurring at the molecular level when the low-affinity Cambrian-like NCBD evolved higher affinity for its protein ligand CID.

Recent works suggest that IDPs can adopt multiple strategies for recognizing their partners. Gianni and co-workers proposed the concept of templated folding, where the folding of the IDP is modulated, or templated, by its binding partner, as shown for cMyb/KIX ${ }^{40}$, MLL/KIX ${ }^{41}$ and $\mathrm{N}_{\mathrm{TAIL}} / \mathrm{XD}^{42,43}$. Similar ideas were put forward by Zhou and coworkers based 
on experiments on WASP GBD/Cdc42 and formulated in terms of multiple dock-andcoalesce pathways ${ }^{44}$. On the other hand, studies on disordered domains from BH3-only proteins binding to BCL-2 family proteins suggest conservation of $\phi$ values and a more robust folding mechanism ${ }^{45}$. We recently showed by double mutants and simulation that a high plasticity in terms of formation of native hydrophobic interactions in the transition state exists for human $\mathrm{NCBD} / \mathrm{CID}^{15}$ where both partner are very flexible, in agreement with templated folding.

In the present study, by comparing the TSs for formation of human and Cambrian-like NCBD/CID complexes, we demonstrate that, while similar core interacting regions have been conserved throughout evolution, the interaction between the two proteins has evolved from a more ordered ancestral TS to the heterogenous and plastic behavior observed in the human complex. We find that the fraction of CID helical content in the transition state is overall conserved, with intermediate values in C $\alpha 1$ (slightly higher in human than in Cambrian-like $\mathrm{NCBD} / \mathrm{CID}$ ) and low values in C $\alpha 2 / 3$. Conversely, we observe that the transition state of the low-affinity Cambrian-like complex has more native-like features in terms of hydrophobic interactions (higher $\phi$-values) as compared to the human one, with clear site-specific differences such as residues Leu2067 Leu2087 and Leu2096 of NCBD. In the ancestral TS, fewer but more native-like contacts are required to be formed (Figure S5 and S6) and proper NCBD tertiary structure (regulating $\mathrm{N} \alpha 1-\mathrm{N} \alpha 2$ orientation) is achieved before CID binding. Vice-versa, in human TS numerous transient inter-molecular interactions are engaged (Figure S6), involving a large number of residues of both CID and NCBD.

In the homeodomain family of proteins a spectrum of folding mechanisms ranging from nucleation-condensation to diffusion-collision was previously observed ${ }^{46}$. Furthermore, it has 
been suggested that the two mechanism can be related to the balance between hydrophobic and electrostatic interactions ${ }^{47}$. Mutational studies on IDPs ${ }^{13,40,41,48-53}$ are more or less consistent with apparent two-state kinetics and the nucleation-condensation mechanism of globular proteins ${ }^{54}$, i.e. cooperative, simultaneous formation of all non-covalent interactions around one well defined core. Salient features of this mechanism are linear Brønsted plots and fractional $\phi$-values. One alternative mechanism would be independently folding structural elements, which dock to form the tertiary structure as formulated in the diffusion-collision model ${ }^{46,55}$. In such scenario, Brønsted plots would be more scattered and the $\phi$-values be both low and high and clustered in structurally contiguous contexts and even separated into two or more folding nuclei. Our comparison of secondary and tertiary structure formation in human versus Cambrian-like NCBD/CID is therefore interesting since it shows that the folding of certain elements of secondary structure can be distinct from others, and that they may or may not be part of an extended folding nucleus. The Brønsted plot for Cambrian-like NCBD/CID shows a larger scatter than that for human NCBD/CID (Fig. 2 d). Whereas C $\alpha 1$ of both $\mathrm{CID}_{1 \mathrm{R}}{ }^{\mathrm{ML}}$ and human CID displays fractional $\phi$-values, C $\alpha 2 / 3$ have $\phi$-values of zero (Fig. 4). Thus, $\mathrm{C} \alpha 1$ may function as a well-defined folding nucleus around which remaining structure condensate, as observed for high-affinity human NCBD. However, C $\alpha 1$ may also be part of a more extended folding nucleus together with hydrophobic tertiary interactions as in lowaffinity Cambrian-like NCBD/CID (Fig. 2-4), but not to the extent that we define it as two separate folding nuclei. The Cambrian-like NCBD/CID shows therefore an intermediate behavior between nucleation-condensation and diffusion-collision mechanism, that shifted towards nucleation-condensation during evolution. Three other IDP interactions with more than one helical segment, Hif- $1 \alpha \mathrm{CAD}^{53}$, TAD-STAT2 ${ }^{52}$, and $\mathrm{pKID}^{56}$ (all binding to KIX), do not display this behavior, but show mainly low $\phi$-values $(<0.2)$ with only one or a few higher ones. Thus, so far, nucleation-condensation appears more prevalent for globular protein 
domains $^{57}$, as well as for IDPs in disorder-to-order transitions. It will be interesting to see whether other IDPs with several secondary structure elements display any distinct distribution of $\phi$-values.

\section{Materials and methods}

\section{Ancestral and human protein sequences.}

The reconstruction of ancestral sequences of NCBD (from the CREBBP/p300 protein family) and CID (from the NCOA/p160/SRC protein family) has been described in detail before ${ }^{20}$. Briefly, protein sequences in these families from various phyla were aligned and the ancestral protein sequences of NCBD and CID were predicted using a maximum likelihood (ML) method. The ML ancestral protein variants of $\mathrm{NCBD}$ and $\mathrm{CID}, \mathrm{NCBD}_{\mathrm{D} / \mathrm{P}}^{\mathrm{ML}}$ and $\mathrm{CID}_{1 \mathrm{R}}{ }^{\mathrm{ML}}$, were used as "wildtypes" in this study. The human NCBD protein was composed of residues 2058-2116 from human CREBBP (UniProt ID: Q92793) and the human CID protein was composed of residues 1018-1088 from human NCOA3/ACTR (UniProt ID: Q9Y6Q9), in accordance with previous studies on the human protein domains ${ }^{16,26,29}$. The reconstructed ancestral sequences of NCBD and CID were shortened to contain only the evolutionarily more well-conserved regions that form a well-defined structure upon association with the other domain. Thus, the ancestral NCBD variant was composed of residues corresponding to 2062-2109 in human CREBBP and the ancestral CID variant was composed of residues corresponding to 1040-1081 in human NCOA3/ACTR.

\section{Cloning and mutagenesis.}

The cDNA sequences for the protein variants used in the study were purchased from GenScript and the proteins were N-terminally tagged with a 6xHis-Lipo domain. The mutants 
were generated using a whole plasmid PCR method. The primers were typically two complementary 33-mer oligonucleotides with mis-matching bases at the site of the mutation, which were flanked on each side by 15 complementary bases. The annealing temperature in the PCR reactions was between $55-65^{\circ} \mathrm{C}$ and the reactions were run for 20 cycles. The products were transformed into E. coli XL-1 Blue Competent Cells and selected on LB agar plates with $100 \mu \mathrm{g} / \mathrm{mL}$ ampicillin. The plasmids were purified using the PureYield ${ }^{\mathrm{TM}}$ Plasmid Miniprep System (Promega).

\section{Protein expression and purification.}

The plasmids encoding the protein constructs were transformed into E. coli BL-21 DE3 pLysS (Invitrogen) and selected on LB agar plates with $35 \mu \mathrm{g} / \mathrm{mL}$ chloramphenicol and 100 $\mu \mathrm{g} / \mathrm{mL}$ ampicillin. Colonies were used to inoculate $\mathrm{LB}$ media with $50 \mu \mathrm{g} / \mathrm{mL}$ ampicillin and the cultures were grown at $37^{\circ} \mathrm{C}$ to reach $\mathrm{OD}_{600} 0.6-0.7$ prior to induction with $1 \mathrm{mM}$ isopropyl $\beta$-D-1-thiogalactopyranoside and overnight expression at $18{ }^{\circ} \mathrm{C}$. The cells were lysed by sonication and centrifuged at approximately $50,000 \mathrm{~g}$ to remove cell debris. The lysate was separated on a Ni Sepharose 6 Fast Flow (GE Healthcare) column using $30 \mathrm{mM}$ Tris- $\mathrm{HCl} \mathrm{pH} 8.0,500 \mathrm{mM} \mathrm{NaCl}$ as the binding buffer and $30 \mathrm{mM}$ Tris- $\mathrm{HCl} \mathrm{pH} 8.0,500 \mathrm{mM}$ $\mathrm{NaCl}, 250 \mathrm{mM}$ imidazol as the elution buffer. The 6xHis-Lipo tag was cleaved off using Thrombin (GE Healthcare) and the protein was separated from the cleaved tag using the same column and buffers as described above. Lastly, the protein was separated on a RESOURCETM reversed phase chromatography column (GE Healthcare) using a 0-70 \% acetonitrile gradient. The purity of the protein was verified by the single-peak appearance on the chromatogram or by SDS-PAGE. The identity was verified by MALDI-TOF mass spectrometry. The fractions containing pure protein were lyophilized and the concentration of the protein was measured by absorption spectrometry at $280 \mathrm{~nm}$ for variants that contained a Tyr or Trp residue. For the 
proteins which lacked a Tyr or Trp residue, absorption at $205 \mathrm{~nm}$ was used to estimate the concentration. The extinction coefficient for human CID was previously determined by amino acid analysis to $250,000 \mathrm{M}^{-1} \mathrm{~cm}^{-1}$ at $205 \mathrm{~nm}$. For the shorter ancestral variants, the extinction coefficient was calculated based on the amino acid sequence ${ }^{58}$.

\section{Design and evaluation of $\mathrm{NCBD}_{\mathrm{D} / \mathrm{P}^{\mathrm{ML}}}$ Trp variants.}

In order to perform fluorescence-monitored stopped-flow kinetic experiments, a fluorescent probe is required. As both NCBD and CID lack Trp residues, which provides the best sensitivity in fluorescence-monitored experiments, several $\mathrm{NCBD}_{\mathrm{D} / \mathrm{P}}{ }^{\mathrm{ML}}$ variants with $\operatorname{Trp}$

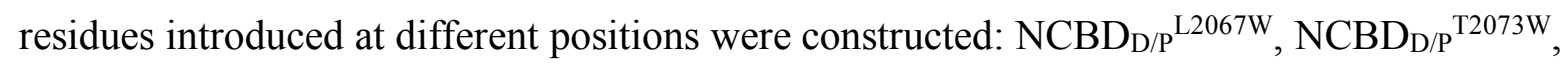

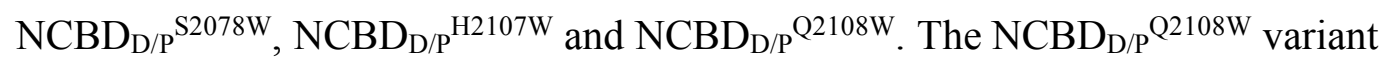
corresponds to the $\mathrm{NCBD}_{\text {Human }}{ }^{\mathrm{Y} 2108 \mathrm{~W}}$ variant, which was used previously as a "pseudowildtype" in stopped flow kinetic experiments ${ }^{15,16,29}$. These $\mathrm{NCBD}_{\mathrm{D} / \mathrm{P}}{ }^{\mathrm{ML}} \operatorname{Trp}$ variants were assessed based on secondary structure content and stability of complex with CID using farUV circular dichroism (CD) spectroscopy, and by kinetic and equilibrium parameters from stopped-flow fluorescence spectroscopy and isothermal titration calorimetry (ITC), in order to find an engineered $\mathrm{NCBD}_{\mathrm{D} / \mathrm{P}} \mathrm{ML}$ variant with similar biophysical properties to the wildtype $\mathrm{NCBD}_{\mathrm{D} / \mathrm{P}} \mathrm{ML}^{\mathrm{ML}}$ (Figure $\mathrm{S} 1$ ). The $\mathrm{NCBD}_{\mathrm{D} / \mathrm{P}}^{\mathrm{T} 2073 \mathrm{~W}}$ variant displayed the most similar behavior to $\mathrm{NCBD}_{\mathrm{D} / \mathrm{P}^{\mathrm{ML}}}$. Our data showed that the structural content, complex stability as well as affinity of this Trp variant was highly similar to $\mathrm{NCBD}_{\mathrm{D} / \mathrm{P}}{ }^{\mathrm{ML}}$ (Figure $\mathrm{S} 1$ ). Thus, our data validated the use of $\mathrm{NCBD}_{\mathrm{D} / \mathrm{P}}^{\mathrm{T} 2073 \mathrm{~W}}$ variant as a representative of $\mathrm{NCBD}_{\mathrm{D} / \mathrm{P}^{\mathrm{ML}}}$ and all stopped flow kinetic experiments for the ancestral Cambrian-like complex were performed using the "pseudowildtype" $\mathrm{NCBD}_{\mathrm{D} / \mathrm{P}}{ }^{\mathrm{T} 2073 \mathrm{~W}}$ variant, which we denote $\mathrm{NCBD}_{\mathrm{D} / \mathrm{P}^{\mathrm{pWT}}}$.

\section{Stopped-flow spectroscopy and calculation of $\phi$-values.}


The kinetic experiments were conducted using an upgraded SX-17MV Stopped-flow spectrofluorometer (Applied Photophysics). The excitation wavelength was set to $280 \mathrm{~nm}$ and the emitted light was detected after passing through a $320 \mathrm{~nm}$ long-pass filter. All experiments were performed at $4{ }^{\circ} \mathrm{C}$ and the default buffer for all experiments was $20 \mathrm{mM}$ sodium phosphate $\mathrm{pH} 7.4,150 \mathrm{mM} \mathrm{NaCl}$. In order to promote secondary and tertiary structure formation of some structurally destabilized NCBD mutants, the experimental buffer was supplemented with $0.7 \mathrm{M}$ trimethylamine N-oxide (TMAO; Figure S2 c-d). Typically, in kinetic experiments the concentration of NCBD was kept constant at 1-2 $\mu \mathrm{M}$ and the concentration of CID was varied between 1-10 $\mu \mathrm{M}$. Experiments where the concentration of CID was kept constant while NCBD was varied were also performed to check for consistency of the obtained results. In these experiments, CID was held constant at $2 \mu \mathrm{M}$ and NCBD was varied between 2-10 $\mu \mathrm{M}$. The kinetic binding curves with NCBD in excess was in good agreement with those using CID in excess, but since the quality of the kinetic traces were better when CID was in excess, these experiments were used to determine the kinetic parameters for the different variants reported in the paper. All experiments were performed using the pseudo wildtype NCBD variants, which was the $\mathrm{NCBD}_{\mathrm{D} / \mathrm{P}} \mathrm{T}^{\mathrm{T} 2073 \mathrm{~W}}$ and $\mathrm{NCBD}_{\text {Human }}{ }^{\mathrm{Y} 2108 \mathrm{~W}}$ variants. These variants are denoted as $\mathrm{NCBD}_{\mathrm{D} / \mathrm{P}}{ }^{\mathrm{pWT}}$ and $\mathrm{NCBD}_{\text {Human }}{ }^{\mathrm{pWT}}$, respectively.

The dissociation rate constant $k_{\text {off }}$ can be determined from binding experiments, but the accuracy decreases whenever $k_{o b s}$ values are much larger than $k_{\text {off }}$ or when $k_{\text {off }}$ is very low. In the present study, displacement experiments were performed for protein complexes with $k_{\text {off }}$ values below $30 \mathrm{~s}^{-1}$ in binding experiments. In displacement experiments, an unlabeled NCBD variant (without Trp) was used to displace the different $\mathrm{NCBD}_{\mathrm{D} / \mathrm{P}}{ }^{\mathrm{pWT}}$ or $\mathrm{NCBD}_{\mathrm{Human}}{ }^{\mathrm{pWT}}$ 
variants from the complexes. The $k_{o b s}$ value at 20 -fold excess of the unlabeled NCBD variant was taken as an estimate of the dissociation rate constant, $k_{\text {off }}$.

The $\phi$-values for each mutant were computed using the rate constants that were obtained in the stopped-flow measurements (e.g $k_{o n}$ and $k_{\text {off }}$ ) using Equations 1-3.

$$
\begin{array}{ll}
\Delta \Delta \mathrm{G}_{\mathrm{TS}}=\mathrm{RT} \ln \left(k_{o n}{ }^{\mathrm{mt}} / k_{o n}{ }^{\mathrm{wt}}\right) & (\text { Equation 1) } \\
\Delta \Delta \mathrm{G}_{\mathrm{EQ}}=\mathrm{RT} \ln \left(K_{D}{ }^{\mathrm{wt}} / K_{D}{ }^{\mathrm{mt}}\right) & \text { (Equation 2) } \\
\phi \text {-value }=\Delta \Delta \mathrm{G}_{\mathrm{TS}} / \Delta \Delta \mathrm{G}_{\mathrm{EQ}} & \text { (Equation 3) }
\end{array}
$$

\section{CD spectroscopy.}

Far-UV circular dichroism (CD) spectra were acquired using a J-1500 spectrophotometer (JASCO) in $20 \mathrm{mM}$ sodium phosphate buffer $\mathrm{pH} 7.4,150 \mathrm{mM} \mathrm{NaCl}$ at $4{ }^{\circ} \mathrm{C}$. The bandwidth was $1 \mathrm{~nm}$, scanning speed $50 \mathrm{~nm} / \mathrm{min}$ and data pitch $1 \mathrm{~nm}$. The protein concentrations were between $20-40 \mu \mathrm{M}$ for all protein variants and each spectrum was typically an average of 2-3 individual spectra. The thermal denaturation experiments of the protein complexes were performed by monitoring the CD signal of $20 \mu \mathrm{M}$ NCBD in complex with $20 \mu \mathrm{M}$ CID at 222 $\mathrm{nm}$ in the same experimental buffer as above and over a temperature range of $4-95{ }^{\circ} \mathrm{C}$. For these experiments, the heating speed was $1{ }^{\circ} \mathrm{C} / \mathrm{min}$ with 5 seconds waiting time at each data point and data was acquired every $1{ }^{\circ} \mathrm{C}$.

\section{NMR spectroscopy.}

NMR samples were prepared by mixing the labelled NCBD or CID solution with excess amount of unlabeled CID or NCBD solution, followed by lyophilization and rehydration. The final samples had a labelled NCBD or CID concentration of approximately $0.5 \mathrm{mM}$ and a phosphate buffer concentration of $20 \mathrm{mM}$ at $\mathrm{pH}$ 7. During dissolution, $0.01 \%$ 
$\mathrm{NaN}_{3}$ and $10 \% \mathrm{D}_{2} \mathrm{O}$ were added. All NMR spectra were recorded at $25{ }^{\circ} \mathrm{C}$ on a $600 \mathrm{MHz}$ Bruker Avance Neo NMR spectrometer equipped with a TCI cryo-probe. The ${ }^{1} \mathrm{H}{ }^{15} \mathrm{~N}$ HSQC spectra were collected with 2048 data points in $\omega_{2} /{ }^{1} \mathrm{H}$ dimension and 256 data points in $\omega_{1} /{ }^{15} \mathrm{~N}$ dimension; 4 or 8 scans were taken. All spectra were processed with TopSpin 3.2 and analyzed with Sparky $3.115^{59}$. During this analysis, a downfield shift of $1.0 \mathrm{ppm}$ in ${ }^{15} \mathrm{~N}$ dimension and a downfield shift of $0.13 \mathrm{ppm}$ in ${ }^{1} \mathrm{H}$ dimension were specifically applied to the ppm scale for ${ }^{15} \mathrm{~N}$ HSQC spectrum of unlabeled $\mathrm{CID}_{1 \mathrm{R}}{ }^{\mathrm{ML}}$ bound to ${ }^{15} \mathrm{~N}$-labelled $\mathrm{NCBD}_{\mathrm{D} / \mathrm{P}^{\mathrm{pWT}}}$.

\section{Isothermal titration calorimetry.}

Isothermal titration calorimetry measurements were performed at $25^{\circ} \mathrm{C}$ in a MicroCal $\mathrm{iTC}_{200}$ System (GE Healthcare). The proteins were dialyzed simultaneously in the same experimental buffer (20 mM sodium phosphate $\mathrm{pH} 7.4,150 \mathrm{mM} \mathrm{NaCl})$ in order to reduce buffer mismatch. The concentration of NCBD in the cell was 12-50 $\mu \mathrm{M}$ (depending on variant) and the concentration of CID in the syringe was between 120-500 $\mu \mathrm{M}$, depending on NCBD concentration, such that a 1:2 stoichiometry was achieved at the end of each experiment. The data were fitted using the built-in software to a two-state binding model.

\section{Data analysis using numerical integration.}

The stopped flow kinetic data sets were fitted using the KinTek Explorer software (KinTek Corporation $)^{60,61}$. The software employs numerical integration to simulate and fit reaction profiles directly to a mechanistic model. Scaling factors were used to correct for small fluctuations in lamp intensity and errors in concentration, but they were generally close to 1 . In cases where the signal-to-noise in the obtained data was low, scaling factors were not applied. For some more-than-one-step models, two-dimensional confidence contour plots were computed to assess confidence limits for each parameter and co-variation between 
parameters. An estimated real time zero of the stopped flow instrument of $-1.25 \mathrm{~ms}$ was used to adjust the timeline in order to obtain correct kinetic amplitudes. The fitted data was exported and graphs were created in GraphPad Prism vs. 6.0 (GraphPad Software).

\section{MD simulations of the transition state ensembles.}

The transition state for formation of the human complex was previously determined by means of $\phi$-value restrained molecular dynamics simulations ${ }^{24}$. Here, the same procedure was followed to determine the TS of the ancestral CID-NCBD complex. The simulations were performed with GROMACS $2018^{62}$ and the PLUMED2 software ${ }^{63}$, using the Amber03w force field ${ }^{64}$ and the TIP4P/2005 water model ${ }^{65}$. The initial conformation was taken from available PDB structure (6ES5) ${ }^{31}$ and modified with Pymol ${ }^{66}$ to account for the T2073W mutation. The structure was solvated with $\sim 6700 / 16800$ water molecules (for native state and TS simulations, respectively), neutralized, minimized and equilibrated at the temperature of $278 \mathrm{~K}$ using the Berendsen thermostat ${ }^{67}$. Production simulations were run in the canonical ensemble, thermosetting the system using the Bussi thermostat ${ }^{68}$; bonds involving hydrogens were constrained with the LINCS algorithm ${ }^{69}$, electrostatic was treated by using the particle mesh Ewald scheme ${ }^{70}$ with a short-range cut-off of $0.9 \mathrm{~nm}$ and van der Waals interaction cutoff was set to $0.9 \mathrm{~nm}$.

A reference native state simulation, at the temperature of $278 \mathrm{~K}$, was performed to determine native contacts. Firstly, we ran a 40 ns long restrained simulation to enforce agreement with atomic inter-molecular upper distances previously determined from NMR experiments ${ }^{31}$ : to this aim lower wall restraints were applied on the NOE-converted distances. Subsequently, an unrestrained $280 \mathrm{~ns}$ long simulation was performed and the last $200 \mathrm{~ns}$ were used to determine native contacts: given two residues that are not nearest neighbors, native contacts 
are defined as the number of heavy side-chain atoms within $0.6 \mathrm{~nm}$ in at least $50 \%$ of the frames.

The TS ensemble of the ancestral complex was determined via $\phi$-value restrained MD simulations, following a standard procedure based on the interpretation of $\phi$-value analysis in terms of fraction of native contacts ${ }^{24,71,72}$. Herein, restraints (in the form of a pseudo energy term accounting for the square distance between experimental and simulated $\phi$-values) are added to the force field to maximize the agreement with the experimental data: the underlying hypothesis is that structures reproducing all the measured $\phi$-values are good representations of the TS. From each conformation the $\phi$-value for a residue is back-calculated as the fraction of the native contact (determined from the native state simulation) that it makes, implying that only $\phi$-values between 0 and 1 can be used as restraints. Totally, we included $11 \phi$-values in this range, all based on single conservative point mutations. Mutations involving charged amino acids (namely, K2075M, involved in intermolecular interactions, and the Ala $\rightarrow$ Gly substitutions at positions D1050 and R1069, probing the helical content of CID helices C $\alpha 1$ and $\mathrm{C} \alpha 2$, respectively) were excluded; we however verified that the structural ensemble obtained could provide a consistent interpretation of the associated $\phi$-values. A list of the $\phi$ values used in the ancestral and human TS simulations is reported in Table S1. The TS ensemble was generated using simulated annealing, performing 1334 annealing cycles, each $150 \mathrm{ps}$ long, in which the temperature was varied between $278 \mathrm{~K}$ and $378 \mathrm{~K}$, for a total simulation time of $200 \mathrm{~ns}$. The TS was determined using only the structures sampled at the reference temperature of $278 \mathrm{~K}$ in the last $150 \mathrm{~ns}$ of simulation, resulting in an ensemble of $\sim 5400$ conformations.

\section{Acknowledgements}


This work was funded by the Swedish Research Council grant 2016-04965 (to P.J.). We used the NMR Uppsala infrastructure, which is funded by the Department of Chemistry - BMC and the Disciplinary Domain of Medicine and Pharmacy. C.C. acknowledges CINECA for an award under the ISCRA initiative, for the availability of high-performance computing resources and support.

\section{Author contributions}

E.K. and P.J. conceived and designed the project. E.K., A.E., Z.A.T., F.S., E.A. and W.Y. performed experiments and analyzed data. C.P. and C.C. designed, performed and analyzed all MD simulations. E.K., C.P., C.C., and P.J. interpreted the data and wrote the paper.

\section{Competing interests}

The authors declare no competing interests.

\section{References}

1. Oates, M. E. et al. D2P2: database of disordered protein predictions. Nucleic Acids Res. 41, D508 (2013).

2. Tantos, A., Han, K.-H. \& Tompa, P. Intrinsic disorder in cell signaling and gene transcription. Mol. Cell. Endocrinol. 348, 457-465 (2012).

3. Thornton, J. W. Resurrecting ancient genes: experimental analysis of extinct molecules. Nat. Rev. Genet. 5, 366-375 (2004).

4. Brown, C. J., Johnson, A. K. \& Daughdrill, G. W. Comparing Models of Evolution for Ordered and Disordered Proteins. Mol. Biol. Evol. 27, 609-621 (2010).

5. Brown, C. J. et al. Evolutionary Rate Heterogeneity in Proteins with Long Disordered Regions. J. Mol. Evol. 55, 104-110 (2002).

6. Xia, Y., Franzosa, E. A. \& Gerstein, M. B. Integrated Assessment of Genomic Correlates of Protein Evolutionary Rate. PLoS Comput. Biol. 5, e1000413 (2009).

7. Pancsa, R., Zsolyomi, F. \& Tompa, P. Co-Evolution of Intrinsically Disordered Proteins with Folded Partners Witnessed by Evolutionary Couplings. doi:10.3390/ijms19113315

8. Dyson, H. J. \& Wright, P. E. Role of Intrinsic Protein Disorder in the Function and Interactions of the Transcriptional Coactivators CREB-binding Protein (CBP) and p300. J. Biol. Chem. 291, 6714-22 (2016).

9. Demarest, S. J., Deechongkit, S., Dyson, H. J., Evans, R. M. \& Wright, P. E. Packing, specificity, and mutability at the binding interface between the p160 coactivator and CREB-binding protein Specificity of binding between proteins using amphipathic 
helices is generally defined by the three-dimensional topology. Gorina and Pavletich 13, 203-210 (1992).

10. Demarest, S. J. et al. Mutual synergistic folding in recruitment of CBP/p300 by $\mathrm{p} 160$ nuclear receptor coactivators. Nature 415, 549-553 (2002).

11. Lee, C. W., Martinez-Yamout, M. A., Dyson, H. J. \& Wright, P. E. Structure of the p53 Transactivation Domain in Complex with the Nuclear Receptor Coactivator Binding Domain of CREB Binding Protein. Biochemistry 49, 9964-9971 (2010).

12. Hiscott, J. \& Lin, R. IRF-3 releases its inhibitions. Structure 13, 1235-6 (2005).

13. Dogan, J., Mu, X., Engström, Å. \& Jemth, P. The transition state structure for coupled binding and folding of disordered protein domains. Sci. Rep. 3, 2076 (2013).

14. Jemth, P., Mu, X., Engström, Å. \& Dogan, J. A frustrated binding interface for intrinsically disordered proteins. J. Biol. Chem. 289, 5528-33 (2014).

15. Karlsson, E. et al. A structurally heterogeneous transition state underlies coupled binding and folding of disordered proteins. J. Biol. Chem. 294, 1230-1239 (2019).

16. Dogan, J., Schmidt, T., Mu, X., Engström, Å. \& Jemth, P. Fast Association and Slow Transitions in the Interaction between Two Intrinsically Disordered Protein Domains. J. Biol. Chem. 287, 34316-34324 (2012).

17. Zosel, F., Mercadante, D., Nettels, D. \& Schuler, B. A proline switch explains kinetic heterogeneity in a coupled folding and binding reaction. Nat. Commun. 9, 3332 (2018).

18. Sturzenegger, F. et al. Transition path times of coupled folding and binding reveal the formation of an encounter complex. Nat. Commun. 9, 4708 (2018).

19. Jemth, P., Mu, X., Engström, A. \& Dogan, J. A frustrated binding interface for intrinsically disordered proteins. J. Biol. Chem. 289, 5528-33 (2014).

20. Hultqvist, G. et al. Emergence and evolution of an interaction between intrinsically disordered proteins. Elife 6, (2017).

21. Jemth, P. et al. Structure and dynamics conspire in the evolution of affinity between intrinsically disordered proteins. Sci. Adv. 4, (2018).

22. Matouschek, A., Kellis, J. T., Serrano, L. \& Fersht, A. R. Mapping the transition state and pathway of protein folding by protein engineering. Nature 340, 122-126 (1989).

23. Yang, J., Gao, M., Xiong, J., Su, Z. \& Huang, Y. Features of molecular recognition of intrinsically disordered proteins via coupled folding and binding. Protein Sci. pro.3718 (2019). doi:10.1002/pro.3718

24. Karlsson, E. et al. A structurally heterogeneous transition state underlies coupled binding and folding of disordered proteins. J. Biol. Chem. (2018). doi:10.1074/jbc.RA118.005854

25. Sato, S., Religa, T. L. \& Fersht, A. R. $\Phi$-Analysis of the Folding of the B Domain of Protein A Using Multiple Optical Probes. J. Mol. Biol. 360, 850-864 (2006).

26. Karlsson, E. et al. A structurally heterogeneous transition state underlies coupled binding and folding of disordered proteins. J. Biol. Chem. jbc.RA118.005854 (2018). doi:10.1074/jbc.RA118.005854

27. Iešmantavičius, V., Dogan, J., Jemth, P., Teilum, K. \& Kjaergaard, M. Helical Propensity in an Intrinsically Disordered Protein Accelerates Ligand Binding. Angew. Chemie Int. Ed. 53, 1548-1551 (2014).

28. Fersht, A. R. \& Sato, S. -Value analysis and the nature of protein-folding transition states. Proc. Natl. Acad. Sci. 101, 7976-7981 (2004).

29. Dogan, J., Mu, X., Engström, Å. \& Jemth, P. The transition state structure for coupled binding and folding of disordered protein domains. Sci. Rep. 3, 2076 (2013).

30. Marc-Olivier Ebert, $\$$, Sung-Hun Bae, H. Jane Dyson, and \& Wright*, P. E. NMR Relaxation Study of the Complex Formed Between CBP and the Activation Domain of the Nuclear Hormone Receptor Coactivator ACTR †. (2008). doi:10.1021/BI701767J 
31. Jemth, P. et al. Structure and dynamics conspire in the evolution of affinity between intrinsically disordered proteins. Sci. Adv. 4, eaau4130 (2018).

32. Kabsch, W. \& Sander, C. Dictionary of protein secondary structure: Pattern recognition of hydrogen-bonded and geometrical features. Biopolymers 22, 2577-2637 (1983).

33. Gianni, S., Dogan, J. \& Jemth, P. Distinguishing induced fit from conformational selection. Biophys. Chem. 189, 33-39 (2014).

34. Karlsson, E. et al. Coupled Binding and Helix Formation Monitored by SynchrotronRadiation Circular Dichroism. Biophys. J. 117, 729-742 (2019).

35. Ward, J. J., Sodhi, J. S., McGuffin, L. J., Buxton, B. F. \& Jones, D. T. Prediction and functional analysis of native disorder in proteins from the three kingdoms of life. $J$. Mol. Biol. 337, 635-45 (2004).

36. Schlessinger, A. et al. Protein disorder-a breakthrough invention of evolution? Curr. Opin. Struct. Biol. 21, 412-418 (2011).

37. Dyson, H. J. \& Wright, P. E. Intrinsically unstructured proteins and their functions. Nat. Rev. Mol. Cell Biol. 6, 197-208 (2005).

38. Tompa, P., Szász, C. \& Buday, L. Structural disorder throws new light on moonlighting. Trends Biochem. Sci. 30, 484-489 (2005).

39. Qin, B. Y. et al. Crystal Structure of IRF-3 in Complex with CBP. Structure 13, 1269 1277 (2005).

40. Toto, A. et al. Molecular Recognition by Templated Folding of an Intrinsically Disordered Protein. Sci. Rep. 6, 21994 (2016).

41. Toto, A., Gianni, S., A, T. \& S., G. Mutational Analysis of the Binding-Induced Folding Reaction of the Mixed-Lineage Leukemia Protein to the KIX Domain. Biochemistry 55, 3957-3962 (2016).

42. Bonetti, D., Troilo, F., Brunori, M., Longhi, S. \& Gianni, S. How Robust Is the Mechanism of Folding-Upon-Binding for an Intrinsically Disordered Protein? Biophys. J. 114, 1889-1894 (2018).

43. Toto, A. et al. Binding induced folding: Lessons from the kinetics of interaction between NTAIL and XD. Arch. Biochem. Biophys. 671, 255-261 (2019).

44. Wu, D., Zhou, H.-X., D, W. \& HX., Z. Designed Mutations Alter the Binding Pathways of an Intrinsically Disordered Protein. Sci. Rep. 9, 6172 (2019).

45. Crabtree, M. D. et al. Folding and binding pathways of BH3-only proteins are encoded within their intrinsically disordered sequence, not templated by partner proteins. $J$. Biol. Chem. 293, 9718-9723 (2018).

46. Karplus, M. \& Weaver, D. L. Protein folding dynamics: The diffusion-collision model and experimental data. Protein Sci. 3, 650-668 (2008).

47. Camilloni, C. et al. Towards a structural biology of the hydrophobic effect in protein folding. Sci. Rep. 6, 28285 (2016).

48. Karlsson, O. A. et al. The Transition State of Coupled Folding and Binding for a Flexible $\beta$-Finger. J. Mol. Biol. 417, 253-261 (2012).

49. Haq, S. R. et al. Side-Chain Interactions Form Late and Cooperatively in the Binding Reaction between Disordered Peptides and PDZ Domains. J. Am. Chem. Soc. 134, 599-605 (2012).

50. Giri, R. et al. Structure of the transition state for the binding of c-Myb and KIX highlights an unexpected order for a disordered system. Proc. Natl. Acad. Sci. U. S. A. 110, 14942-7 (2013).

51. JM, R. et al. Interplay between partner and ligand facilitates the folding and binding of an intrinsically disordered protein. Proc. Natl. Acad. Sci. U. S. A. 111, 15420-15425 (2014).

52. Lindström, I. \& Dogan, J. Native Hydrophobic Binding Interactions at the Transition 
State for Association between the TAZ1 Domain of CBP and the Disordered TADSTAT2 Are Not a Requirement. Biochemistry 56, 4145-4153 (2017).

53. Lindström, I. et al. The transition state structure for binding between TAZ1 of CBP and the disordered Hif-1 $\alpha$ CAD. Sci. Rep. 8, 7872 (2018).

54. Itzhaki, L. S., Otzen, D. E. \& Fersht, A. R. The structure of the transition state for folding of chymotrypsin inhibitor 2 analysed by protein engineering methods: evidence for a nucleation-condensation mechanism for protein folding. J. Mol. Biol. 254, 260-88 (1995).

55. Gianni, S. et al. Unifying features in protein-folding mechanisms. Proc. Natl. Acad. Sci. 100, 13286-13291 (2003).

56. Dahal, L., Kwan, T. O. C., Shammas, S. L. \& Clarke, J. pKID Binds to KIX via an Unstructured Transition State with Nonnative Interactions. Biophys. J. 113, 2713-2722 (2017).

57. Fersht, A. R., Itzhaki, L. S., elMasry, N. F., Matthews, J. M. \& Otzen, D. E. Single versus parallel pathways of protein folding and fractional formation of structure in the transition state. Proc. Natl. Acad. Sci. U. S. A. 91, 10426-9 (1994).

58. Anthis, N. J. \& Clore, G. M. Sequence-specific determination of protein and peptide concentrations by absorbance at $205 \mathrm{~nm}$. Protein Sci. 22, 851-858 (2013).

59. Lee, W., Tonelli, M. \& Markley, J. L. NMRFAM-SPARKY: enhanced software for biomolecular NMR spectroscopy. Bioinformatics 31, 1325-7 (2015).

60. Johnson, K. A., Simpson, Z. B. \& Blom, T. Global Kinetic Explorer: A new computer program for dynamic simulation and fitting of kinetic data. Anal. Biochem. 387, 20-29 (2009).

61. Johnson, K. A., Simpson, Z. B. \& Blom, T. FitSpace Explorer: An algorithm to evaluate multidimensional parameter space in fitting kinetic data. Anal. Biochem. 387, 30-41 (2009).

62. Abraham, M. J. et al. GROMACS: High performance molecular simulations through multi-level parallelism from laptops to supercomputers. SoftwareX 1-2, 19-25 (2015).

63. Tribello, G. A., Bonomi, M., Branduardi, D., Camilloni, C. \& Bussi, G. PLUMED 2: New feathers for an old bird. Comput. Phys. Commun. 185, 604-613 (2014).

64. Best, R. B. \& Mittal, J. Protein Simulations with an Optimized Water Model: Cooperative Helix Formation and Temperature-Induced Unfolded State Collapse. $J$. Phys. Chem. B 114, 14916-14923 (2010).

65. Abascal, J. L. F. \& Vega, C. A general purpose model for the condensed phases of water: TIP4P/2005. J. Chem. Phys. 123, 234505 (2005).

66. The PyMOL Molecular Graphics System, Version 1.2r3pre, Schrödinger, LLC.

67. Berendsen, H. J. C., Postma, J. P. M., van Gunsteren, W. F., DiNola, A. \& Haak, J. R. Molecular dynamics with coupling to an external bath. J. Chem. Phys. 81, 3684-3690 (1984).

68. Bussi, G., Donadio, D. \& Parrinello, M. Canonical sampling through velocity rescaling. J. Chem. Phys. 126, 014101 (2007).

69. Hess, B., Bekker, H., Berendsen, H. J. C. \& Fraaije, J. G. E. M. LINCS: A linear constraint solver for molecular simulations. J. Comput. Chem. 18, 1463-1472 (1997).

70. Essmann, U. et al. A smooth particle mesh Ewald method. J. Chem. Phys. 103, 85778593 (1995).

71. Vendruscolo, M., Paci, E., Dobson, C. M. \& Karplus, M. Three key residues form a critical contact network in a protein folding transition state. Nature 409, 641-645 (2001).

72. Paci, E., Vendruscolo, M., Dobson, C. M. \& Karplus, M. Determination of a Transition State at Atomic Resolution from Protein Engineering Data. J. Mol. Biol. 324, 151-163 
bioRxiv preprint doi: https://doi.org/10.1101/2020.03.27.012328; this version posted March 29, 2020. The copyright holder for this preprint (which was not certified by peer review) is the author/funder, who has granted bioRxiv a license to display the preprint in perpetuity. It is made available under aCC-BY-NC-ND 4.0 International license.

(2002).

73. Malatesta, F. The study of bimolecular reactions under non-pseudo-first order conditions. Biophys. Chem. 116, 251-256 (2005). 


\section{Tables}

Table 1. Rate constants of binding for ancestral NCBD and CID variants determined in

stopped flow experiments. The mutants were either helix-modulating mutants of ancestral

CID or deletion mutations in NCBD or CID chosen to probe for native inter- and

intramolecular interactions in the ancestral complex. The rate constants were obtained from

global fitting of the kinetic data sets to a simple two-state model by numerical integration and the error is the standard error from the fit. The association rate constant of the wildtype represents an average of five separate experiments and the error is the standard deviation for these measurements. All experiments were performed in $20 \mathrm{mM}$ sodium phosphate $\mathrm{pH} 7.4$, $150 \mathrm{mM} \mathrm{NaCl}$ at $4{ }^{\circ} \mathrm{C}$.

\begin{tabular}{|c|c|c|c|c|c|c|}
\hline $\begin{array}{l}\mathrm{NCBD}_{\mathrm{D} / \mathrm{P}} \\
\text { variant }\end{array}$ & CID $_{1 \mathrm{R}}$ variant & $k_{o n}\left(\mu \mathbf{M}^{-1} \mathrm{~s}^{-1}\right)$ & $k_{o f f}\left(s^{-1}\right)$ & $\begin{array}{l}\text { Type of } \\
\text { mutation }\end{array}$ & $\begin{array}{c}\mathbf{K}_{\mathbf{D}} \\
(\mu \mathrm{M})\end{array}$ & $\phi$-value \\
\hline pWT & $\mathrm{ML}$ & $30 \pm 3$ & $24.7 \pm 0.3^{\mathrm{a}}$ & - & $\begin{array}{c}0.81 \pm \\
0.07\end{array}$ & - \\
\hline pWT & A1047G & $24.8 \pm 0.2$ & $53.8 \pm 0.8$ & $\begin{array}{c}\text { Helix } \\
\text { modulating } \mathrm{C} \alpha 1\end{array}$ & $\begin{array}{c}2.17 \pm \\
0.03\end{array}$ & $0.21 \pm 0.16$ \\
\hline pWT & D1050A & $31.7 \pm 0.1$ & $21.3 \pm 0.2^{\mathrm{a}}$ & $\begin{array}{c}\text { Helix } \\
\text { modulating } \mathrm{C} \alpha 1\end{array}$ & $\begin{array}{c}0.67 \pm \\
0.01\end{array}$ & - \\
\hline pWT & D1050G & $18.7 \pm 0.2$ & $72 \pm 0.9$ & $\begin{array}{c}\text { Helix } \\
\text { modulating } \mathrm{C} \alpha 1\end{array}$ & $\begin{array}{c}3.85 \pm \\
0.06\end{array}$ & $0.30 \pm 0.01$ \\
\hline pWT & S1054A & $39.0 \pm 0.2$ & $14.9 \pm 0.1^{\mathrm{a}}$ & $\begin{array}{c}\text { Helix } \\
\text { modulating } \mathrm{C} \alpha 1\end{array}$ & $\begin{array}{c}0.38 \pm \\
0.003\end{array}$ & $0.33 \pm 0.21$ \\
\hline pWT & S1054G & $23.2 \pm 0.2$ & $74 \pm 1$ & $\begin{array}{c}\text { Helix } \\
\text { modulating } \mathrm{C} \alpha 1\end{array}$ & $\begin{array}{c}3.19 \pm \\
0.05\end{array}$ & $0.24 \pm 0.01$ \\
\hline pWT & M1062A & $29.8 \pm 0.2$ & $16.1 \pm 0.3^{\mathrm{a}}$ & $\begin{array}{c}\text { Helix } \\
\text { modulating } \mathrm{C} \alpha 2\end{array}$ & $\begin{array}{c}0.54 \pm \\
0.01\end{array}$ & $0.05 \pm 0.36$ \\
\hline pWT & M1062G & $26.3 \pm 0.2$ & $21.2 \pm 0.2^{\mathrm{a}}$ & $\begin{array}{c}\text { Helix } \\
\text { modulating } \mathrm{C} \alpha 2\end{array}$ & $\begin{array}{c}0.81 \pm \\
0.01\end{array}$ & $0.31 \pm 0.06$ \\
\hline pWT & A1065G & $28.5 \pm 0.3$ & $77 \pm 1$ & $\begin{array}{c}\text { Helix } \\
\text { modulating } \mathrm{C} \alpha 2\end{array}$ & $\begin{array}{c}2.70 \pm \\
0.05\end{array}$ & $0.05 \pm 0.12$ \\
\hline pWT & R1069A & $26.0 \pm 0.1$ & $66.7 \pm 0.6$ & $\begin{array}{c}\text { Helix } \\
\text { modulating } \mathrm{C} \alpha 2\end{array}$ & $\begin{array}{c}2.57 \pm \\
0.03\end{array}$ & $0.14 \pm 0.13$ \\
\hline
\end{tabular}


bioRxiv preprint doi: https://doi.org/10.1101/2020.03.27.012328; this version posted March 29, 2020 . The copyright holder for this preprint (which was not certified by peer review) is the author/funder, who has granted bioRxiv a license to display the preprint in perpetuity. It is made available under aCC-BY-NC-ND 4.0 International license.

\begin{tabular}{|c|c|c|c|c|c|c|}
\hline pWT & R1069G & $23.0 \pm 0.6$ & $209 \pm 4$ & $\begin{array}{c}\text { Helix } \\
\text { modulating } \mathrm{C} \alpha 2\end{array}$ & $\begin{array}{c}9.1 \pm \\
0.3\end{array}$ & $0.10 \pm 0.04$ \\
\hline pWT & L1048A & $13.5 \pm 0.1$ & $105 \pm 1$ & $\begin{array}{c}\text { Native } \\
\text { interactions with } \\
\text { Leu2071 }\end{array}$ & $\begin{array}{c}7.8 \pm \\
0.1\end{array}$ & $0.36 \pm 0.07$ \\
\hline pWT & L1049A & $18.7 \pm 0.1$ & $71.8 \pm 0.6$ & $\begin{array}{c}\text { Native } \\
\text { interactions with } \\
\text { Leu2071, } \\
\text { Leu2074 and } \\
\text { Phe2100 }\end{array}$ & $\begin{array}{c}3.84 \pm \\
0.04\end{array}$ & $0.31 \pm 0.10$ \\
\hline pWT & D1053A & $46.4 \pm 0.2$ & $22.3 \pm 0.2^{\mathrm{a}}$ & $\begin{array}{c}\text { Electrostatic } \\
\text { interaction with } \\
\text { Lys2075 and } \\
\text { Arg2104 }\end{array}$ & $\begin{array}{c}0.48 \\
\pm 0.005\end{array}$ & $0.81 \pm 0.36$ \\
\hline pWT & L1055A & $14.0 \pm 0.1$ & $29.0 \pm 0.4^{\mathrm{a}}$ & $\begin{array}{c}\text { Native } \\
\text { interactions with } \\
\text { Leu1064 and } \\
\text { Leu2074 }\end{array}$ & $\begin{array}{c}2.07 \pm \\
0.03\end{array}$ & $0.83 \pm 0.21$ \\
\hline pWT & L1056A & $\begin{array}{l}\text { Too unstable } \\
\text { complex }\end{array}$ & $\begin{array}{l}\text { Too unstable } \\
\text { complex }\end{array}$ & $\begin{array}{c}\text { Native } \\
\text { interactions with } \\
\text { Leu2074 }\end{array}$ & - & - \\
\hline pWT & L1064A & $\begin{array}{l}\text { Too unstable } \\
\text { complex }\end{array}$ & $\begin{array}{l}\text { Too unstable } \\
\text { complex }\end{array}$ & $\begin{array}{c}\text { Native } \\
\text { interactions with } \\
\text { Leu2074 and } \\
\text { Phe } 2100\end{array}$ & - & - \\
\hline pWT & I1067V & $20.4 \pm 0.2$ & $93 \pm 1$ & $\begin{array}{c}\text { Native } \\
\text { interactions with } \\
\text { Leu2074, } \\
\text { Val2086, } \\
\text { Leu2087, } \\
\text { Leu2090 and } \\
\text { Phe2099 }\end{array}$ & $\begin{array}{c}4.56 \pm \\
0.07\end{array}$ & $0.23 \pm 0.09$ \\
\hline pWT & I1067A & $\begin{array}{l}\text { Too unstable } \\
\text { complex }\end{array}$ & $\begin{array}{l}\text { Too unstable } \\
\text { complex }\end{array}$ & $\begin{array}{c}\text { Native } \\
\text { interactions with } \\
\text { Leu2074, } \\
\text { Val2086, } \\
\text { Leu2087, } \\
\text { Leu2090 and } \\
\text { Phe2100 }\end{array}$ & - & - \\
\hline pWT & D1068A & $39.6 \pm 0.2$ & $59.5 \pm 0.7$ & $\begin{array}{c}\text { Electrostatic } \\
\text { interaction with } \\
\text { Arg2104 }\end{array}$ & $\begin{array}{c}1.50 \pm \\
0.02\end{array}$ & $-0.43 \pm 0.26$ \\
\hline pWT & L1071A & $\begin{array}{l}\text { Too unstable } \\
\text { complex }\end{array}$ & $\begin{array}{l}\text { Too unstable } \\
\text { complex }\end{array}$ & $\begin{array}{c}\text { Native } \\
\text { interactions with } \\
\text { Leu2071, } \\
\text { Leu2074, } \\
\text { Val2086, } \\
\text { Leu2087, } \\
\text { Leu2090, } \\
\text { Ala2098, } \\
\text { Ala2099 and } \\
\text { Ile2101 }\end{array}$ & - & - \\
\hline L2067A & ML & $14.8 \pm 0.2$ & $67 \pm 1$ & $\begin{array}{c}\text { Native } \\
\text { interactions with } \\
\text { Ile2089, } \\
\text { Leu2090, } \\
\text { Leu2096 }\end{array}$ & $\begin{array}{c}4.5 \pm \\
0.1\end{array}$ & $0.42 \pm 0.10$ \\
\hline
\end{tabular}




\begin{tabular}{|c|c|c|c|c|c|c|}
\hline L2071A & ML & $22.1 \pm 0.1$ & $17.4 \pm 0.1^{\mathrm{a}}$ & $\begin{array}{c}\text { Native } \\
\text { interactions with } \\
\text { Leu2071, } \\
\text { Ile2089 and } \\
\text { Leu2093 }\end{array}$ & $\begin{array}{l}0.79 \pm \\
0.006\end{array}$ & - \\
\hline L2074A & ML & $\begin{array}{l}\text { Too unstable } \\
\text { complex }\end{array}$ & $\begin{array}{l}\text { Too unstable } \\
\text { complex }\end{array}$ & $\begin{array}{c}\text { Native } \\
\text { interactions with } \\
\text { Leu2071, } \\
\text { Leu2074, } \\
\text { Leu2078, } \\
\text { Leu2086, } \\
\text { Ile2089, } \\
\text { Ala2092, } \\
\text { Leu2093 } \\
\text { and Ile2095 }\end{array}$ & - & \\
\hline K2075M & ML & $14.5 \pm 0.1$ & $26.3 \pm 0.4^{\mathrm{a}}$ & $\begin{array}{c}\text { Electrostatic } \\
\text { interaction with } \\
\text { Asp1053 }\end{array}$ & $\begin{array}{c}1.81 \pm \\
0.03\end{array}$ & $0.92 \pm 0.26$ \\
\hline K2075M & D1053A & $18.0 \pm 0.1$ & $26.2 \pm 0.2$ & - & $\begin{array}{c}1.46 \pm \\
0.01\end{array}$ & \\
\hline L2086A & $\mathrm{ML}$ & $\begin{array}{l}\text { Too unstable } \\
\text { complex }\end{array}$ & $\begin{array}{l}\text { Too unstable } \\
\text { complex }\end{array}$ & $\begin{array}{c}\text { Native } \\
\text { interactions with } \\
\text { Ile1067, } \\
\text { Ala1070 and } \\
\text { Leu1071 }\end{array}$ & - & \\
\hline L2087A & $\mathrm{ML}$ & $15.1 \pm 0.1$ & $26.4 \pm 0.5^{\mathrm{a}}$ & $\begin{array}{c}\text { Native } \\
\text { interactions with } \\
\text { Ala1066, } \\
\text { Ile1067, } \\
\text { Ala1070 and } \\
\text { Leu1071 } \\
\end{array}$ & $\begin{array}{c}1.75 \pm \\
0.04\end{array}$ & $0.91 \pm 0.27$ \\
\hline L2090A & ML & $\begin{array}{l}\text { Too unstable } \\
\text { complex }\end{array}$ & $\begin{array}{l}\text { Too unstable } \\
\text { complex }\end{array}$ & $\begin{array}{c}\text { Native } \\
\text { interactions with } \\
\text { Ile1067, } \\
\text { Ala1070, } \\
\text { Leu1071 and } \\
\text { Ile1073 }\end{array}$ & - & \\
\hline L2096A & ML & $14.9 \pm 0.1$ & $40.7 \pm 0.5$ & $\begin{array}{c}\text { Native } \\
\text { interactions with } \\
\text { Leu2067 and } \\
\text { Leu2090 }\end{array}$ & $\begin{array}{c}2.73 \pm \\
0.04\end{array}$ & $0.59 \pm 0.14$ \\
\hline A2099G & ML & $27.6 \pm 0.3$ & $122 \pm 1$ & $\begin{array}{c}\text { Native } \\
\text { interactions with } \\
\text { Leu2067 }\end{array}$ & $\begin{array}{c}4.42 \pm \\
0.06\end{array}$ & $0.06 \pm 0.09$ \\
\hline $\mathrm{I} 2101 \mathrm{~V}$ & $\mathrm{ML}$ & $29.3 \pm 0.1$ & $23.8 \pm 0.3^{\mathrm{a}}$ & $\begin{array}{c}\text { Native } \\
\text { interactions with } \\
\text { Leu1071, } \\
\text { Ile1073 and } \\
\text { Leu1076 }\end{array}$ & $\begin{array}{c}0.81 \pm \\
0.01\end{array}$ & \\
\hline I2101A & ML & $\begin{array}{l}\text { Too unstable } \\
\text { complex }\end{array}$ & $\begin{array}{l}\text { Too unstable } \\
\text { complex }\end{array}$ & $\begin{array}{c}\text { Native } \\
\text { interactions with } \\
\text { Leu1071, } \\
\text { Ile1073 and } \\
\text { Leu1076 }\end{array}$ & - & \\
\hline R2104M & ML & $\begin{array}{l}\text { Too unstable } \\
\text { complex }\end{array}$ & $\begin{array}{l}\text { Too unstable } \\
\text { complex }\end{array}$ & $\begin{array}{c}\text { Native } \\
\text { interactions with } \\
\text { Asp1068 }\end{array}$ & - & \\
\hline
\end{tabular}




\begin{tabular}{l|l|c|c|}
$\mathrm{R} 2104 \mathrm{M}$ & $\mathrm{D} 1053 \mathrm{~A}$ & $\begin{array}{c}\text { Too unstable } \\
\text { complex }\end{array}$ & $\begin{array}{c}\text { Too unstable } \\
\text { complex }\end{array}$ \\
&
\end{tabular}

${ }^{a}$ The dissociation rate constant was determined in a separate displacement experiment with the same experimental conditions as described above. The $k_{o b s}$ value at 20 -fold excess of the displacing protein was taken as an estimate of $k_{\text {off }}$ along with the Standard Error of the fit to a single exponential function.

Table 2. Rate constants for helix-modulating mutations in helix 2 and helix 3 of human

CID. The rate constants were obtained in fluorescence-monitored stopped flow kinetic experiments. The experimental conditions were $20 \mathrm{mM}$ sodium phosphate buffer $\mathrm{pH} 7.4,150$ $\mathrm{mM} \mathrm{NaCl}$ and the experiments were performed at $4^{\circ} \mathrm{C}$. The errors are Standard Errors from global fitting to a simple two-state model.

\begin{tabular}{|c|c|c|c|c|c|c|}
\hline $\begin{array}{c}\text { NCBD Human } \\
\text { variant }\end{array}$ & $\begin{array}{c}\text { CIDHuman } \\
\text { variant }\end{array}$ & $k_{o n}\left(\underset{1}{\mu} M^{-1} s^{-}\right.$ & $k_{o f f}\left(\mathbf{s}^{-1}\right)$ & $\begin{array}{l}\text { Type of } \\
\text { mutation }\end{array}$ & $K_{D}(\mu M)$ & $\phi$-value \\
\hline pWT & WT & $25.0 \pm 0.1$ & $\begin{array}{c}2.66 \pm \\
0.01^{\mathrm{a}}\end{array}$ & - & $\begin{array}{c}0.11 \pm \\
0.001\end{array}$ & - \\
\hline pWT & E1065A & $24.9 \pm 0.2$ & $\begin{array}{c}2.59 \pm \\
0.01^{\mathrm{a}}\end{array}$ & $\begin{array}{c}\text { Helix } \\
\text { modulating } \\
\mathrm{C} \alpha 2\end{array}$ & $\begin{array}{c}0.10 \pm \\
0.001\end{array}$ & - \\
\hline pWT & E1065G & $23.7 \pm 0.2$ & $7.8 \pm 0.1^{\mathrm{a}}$ & $\begin{array}{c}\text { Helix } \\
\text { modulating } \\
\mathrm{C} \alpha 2 \\
\end{array}$ & $0.33 \pm 0.01$ & $0.04 \pm 0.02$ \\
\hline $\mathrm{pWT}$ & R1069A & $27.7 \pm 0.2$ & $8.8 \pm 0.1^{\mathrm{a}}$ & $\begin{array}{c}\text { Helix } \\
\text { modulating } \\
\mathrm{C} \alpha 2\end{array}$ & $\begin{array}{c}0.32 \pm \\
0.004\end{array}$ & $-0.09 \pm 0.01$ \\
\hline pWT & R1069G & $26.4 \pm 0.4$ & $76 \pm 2$ & $\begin{array}{c}\text { Helix } \\
\text { modulating } \\
\mathrm{C} \alpha 2\end{array}$ & $2.88 \pm 0.09$ & $0.02 \pm 0.01$ \\
\hline pWT & E1075A & $26.5 \pm 0.2$ & $\begin{array}{c}3.12 \pm \\
0.06^{\mathrm{a}}\end{array}$ & $\begin{array}{c}\text { Helix } \\
\text { modulating } \\
\mathrm{C} \alpha 3\end{array}$ & $\begin{array}{c}0.12 \pm \\
0.002\end{array}$ & - \\
\hline pWT & E1075G & $23.7 \pm 0.1$ & $\begin{array}{c}3.44 \pm \\
0.02^{\mathrm{a}}\end{array}$ & $\begin{array}{c}\text { Helix } \\
\text { modulating } \\
\mathrm{C} \alpha 3\end{array}$ & $\begin{array}{c}0.15 \pm \\
0.001\end{array}$ & - \\
\hline
\end{tabular}

${ }^{a}$ The dissociation rate constant $\left(k_{\text {off }}\right)$ was determined in a separate displacement experiment.

The value of $k_{\text {off }}$ was estimated from a measurement with 20 -fold excess of unlabeled NCBD and the errors are the Standard Error from the fit to a single exponential function. 
Table 3. Rate constants of binding of $\mathrm{NCBD}_{\mathrm{D} / \mathrm{P}} \mathrm{L}^{\mathrm{L2067W}}$ to different CID variants

determined in stopped flow experiments. The errors are Standard Errors from global fitting of the kinetic data to a two-state model. All experiments were performed in $20 \mathrm{mM}$ sodium phosphate $\mathrm{pH} 7.4,150 \mathrm{mM} \mathrm{NaCl}$ at $4{ }^{\circ} \mathrm{C}$. In general, the resulting $\phi$-values are similar to the ones obtained using the $\mathrm{NCBD}_{\mathrm{D} / \mathrm{P}^{\mathrm{pWT}}}$ variant with Trp2073 (shown in parenthesis).

\begin{tabular}{|c|c|c|c|c|c|c|}
\hline $\begin{array}{c}\mathrm{NCBD}_{\mathrm{D} / \mathrm{P}^{\mathrm{pWT}}} \\
\text { variant }\end{array}$ & $\begin{array}{c}\text { CID }_{1 \mathrm{R}} \\
\text { variant }\end{array}$ & $k_{\text {on }}\left(\mu \mathbf{M}^{-1} \mathbf{s}^{-1}\right)$ & $k_{o f f}\left(\mathrm{~s}^{-1}\right)$ & $\begin{array}{c}\text { Type of } \\
\text { mutation }\end{array}$ & $\mathbf{K}_{\mathbf{D}}(\boldsymbol{\mu} \mathbf{M})$ & $\phi$-value \\
\hline L2067W & $\overline{\mathrm{ML}}$ & $17.9 \pm 0.1$ & $\begin{array}{l}39.2 \pm \\
0.2\end{array}$ & - & $2.2 \pm 0.02$ & - \\
\hline L2067W & $\mathrm{A} 1047 \mathrm{G}$ & $12.9 \pm 0.1$ & $\begin{array}{l}64.7 \\
\pm 0.6\end{array}$ & $\begin{array}{c}\text { Helix } \\
\text { modulating } \\
\text { C } \alpha 1\end{array}$ & $5.0 \pm 0.1$ & $\begin{array}{c}0.40 \pm 0.02 \\
(0.21 \pm 0.16)\end{array}$ \\
\hline L2067W & L1049A & $9.6 \pm 0.1$ & $\begin{array}{c}52.9 \pm \\
0.2\end{array}$ & $\begin{array}{c}\text { Native } \\
\text { interactions } \\
\text { with } \\
\text { Leu2071, } \\
\text { Leu2074 and } \\
\text { Phe2100 } \\
\end{array}$ & $5.5 \pm 0.1$ & $\begin{array}{c}0.68 \pm 0.03 \\
(0.31 \pm 0.17)\end{array}$ \\
\hline L2067W & D1053A & $29.3 \pm 0.1$ & $\begin{array}{c}25.7 \pm \\
0.1\end{array}$ & $\begin{array}{c}\text { Electrostatic } \\
\text { interaction } \\
\text { with Lys2075 } \\
\text { and Arg2104 }\end{array}$ & $0.88 \pm 0.01$ & $\begin{array}{c}0.54 \pm 0.02 \\
(0.81 \pm 0.36)\end{array}$ \\
\hline L2067W & $\mathrm{I} 1067 \mathrm{~V}$ & $10.7 \pm 0.1$ & $132 \pm 1$ & $\begin{array}{c}\text { Native } \\
\text { interactions } \\
\text { with } \\
\text { Leu2074, } \\
\text { Val2086, } \\
\text { Leu2087, } \\
\text { Leu2090 and } \\
\text { Phe2099 }\end{array}$ & $12.3 \pm 0.1$ & $\begin{array}{c}0.30 \pm 0.01 \\
(0.23 \pm 0.09)\end{array}$ \\
\hline L2067W & A1065G & $14.4 \pm 0.2$ & $125 \pm 1$ & $\begin{array}{c}\text { Helix } \\
\text { modulating } \\
\text { C } \alpha 2\end{array}$ & $8.7 \pm 0.1$ & $\begin{array}{c}0.16 \pm 0.02 \\
(0.05 \pm 0.12)\end{array}$ \\
\hline L2067W & $\bar{D} 1068 \mathrm{~A}$ & $27.0 \pm 0.3$ & $178 \pm 2$ & $\begin{array}{c}\text { Electrostatic } \\
\text { interaction } \\
\text { with Arg2104 }\end{array}$ & $6.6 \pm 0.1$ & $\begin{array}{c}-0.37 \pm 0.02 \\
(-0.43 \pm \\
0.26)\end{array}$ \\
\hline
\end{tabular}




\section{Figures}

(a)

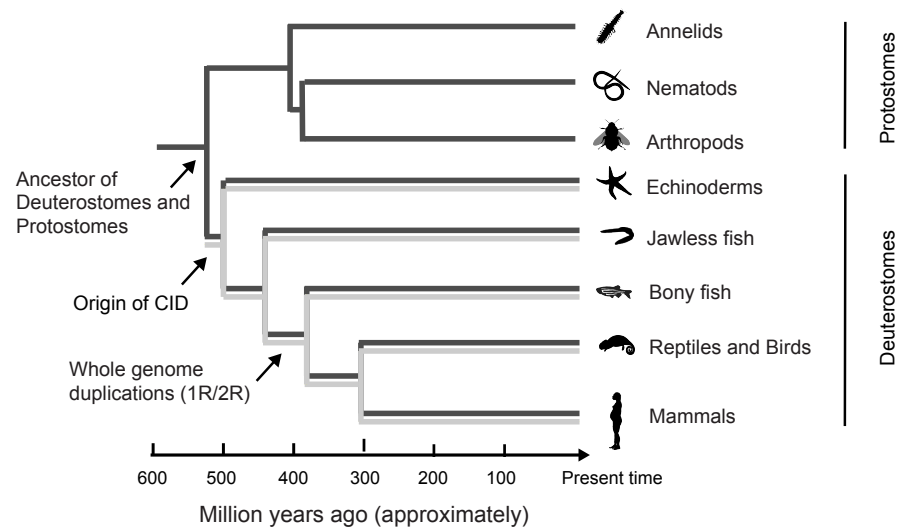

(b)

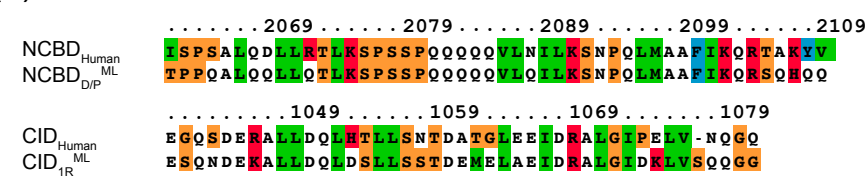

(c)
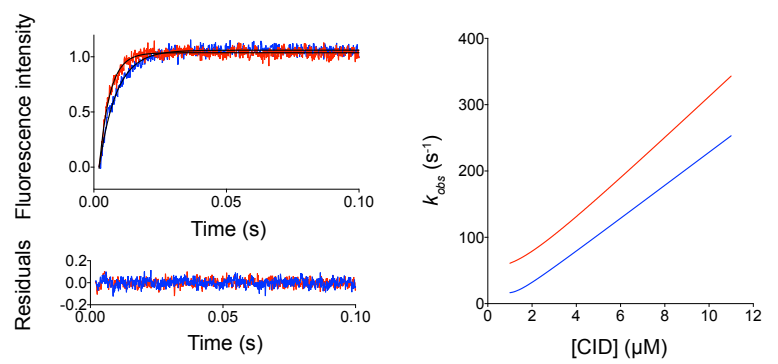

(d)
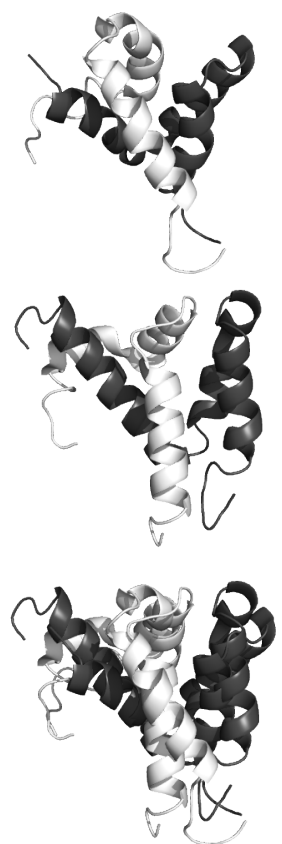

(e)

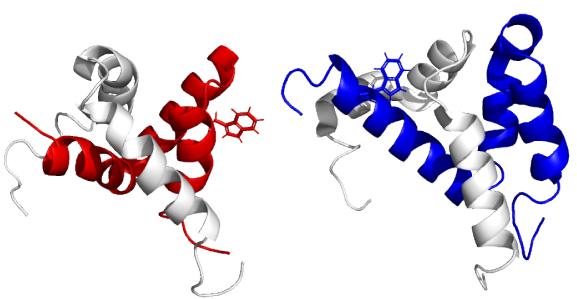

Figure 1. Extant and ancestral NCBD and CID variants. (a) A schematic phylogenetic tree showing the evolutionary relationship between extant species and reconstructed ancestral NCBD (dark grey) and CID (light grey) variants. The schematic animals were obtained from phylopic.org. (b) The sequences of the reconstructed ancestral and extant human NCBD (top) and CID (bottom) that have been used in the study. Human NCBD is from CREBBP and human CID is from NCOA3/ACTR. The color denotes residue type. (c) Examples of typical stopped-flow kinetic traces for the Cambrian-like complex (red) and human complex (blue) to the left. The concentrations used in this example were $1 \mu \mathrm{M}$ NCBD and $6 \mu \mathrm{M}$ CID for both experiments. The kinetic traces were fitted to a single exponential function (shown as a solid black line) and the residuals are displayed below the curve. The figure to the right shows the dependence of the observed rate constant $\left(k_{o b s}\right)$ on CID concentration for the Cambrian-like 
complex (red) and the human complex (blue), using the rate constants obtained in global fitting (Table 2). (d) Solution structures of the Cambrian-like complex (top; PDB entry $6 \mathrm{ES} 5)^{31}$, the human complex (middle; PDB entry $\left.1 \mathrm{KBH}\right)^{10}$ and an alignment of the two complexes (bottom) with NCBD in dark grey and CID in light grey. (e) Structures of the Cambrian-like complex (left; NCBD in red and CID in light grey) and the extant human complex (right; NCBD in blue and CID in light grey) showing the position of the engineered Trp residues as stick model. 
(a)

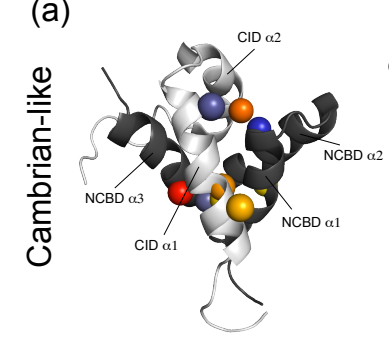

(b)

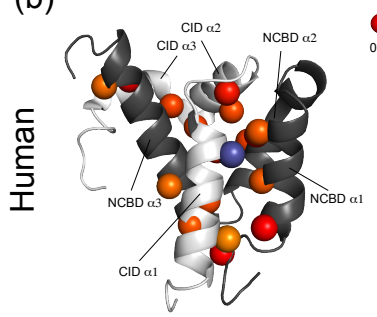

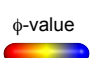
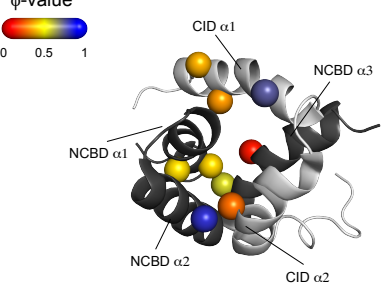

$\phi$-value
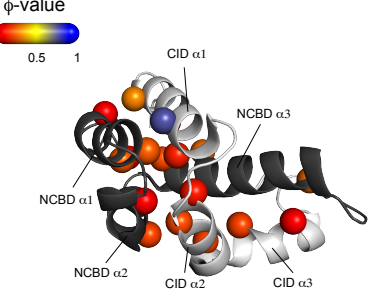

(c)

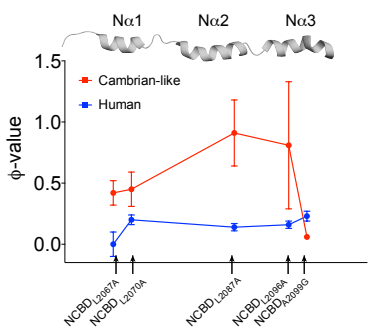

(d)

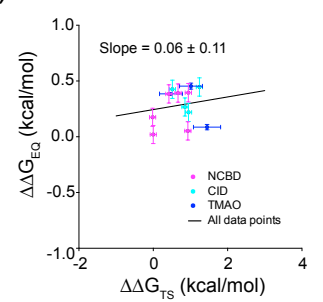

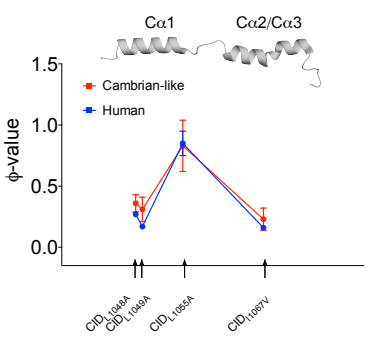

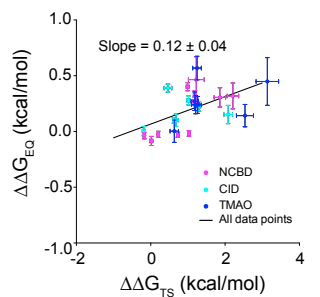

Figure 2. $\phi$-values mapped onto the structures of the Cambrian-like and human

complexes. (a) $\phi$-values for conservative deletion mutations (mostly Leu $\rightarrow$ Ala mutations) in the binding interface of the Cambrian-like complex. NCBD in dark grey and CID in light grey. The two structures represent the same complex from different angles. Most $\phi$-values fall within the intermediate to high $\phi$-value category $(0.3-0.9)$. (b) The previously published $\phi$ values for conservative deletion mutations in the binding interface of the human NCBD/CID complex $^{13}$. Most $\phi$-values are in the low region $(<0.3)$. (c) A site-to-site comparison between $\phi$-values at corresponding positions in the Cambrian-like (red) and human (blue) complexes.

(d) Brønsted plots for the Cambrian-like (left) and human (right) NCBD/CID interaction.

Data for human NCBD/CID were obtained from previous studies ${ }^{13,24}$. All structures were created using PyMOL. 

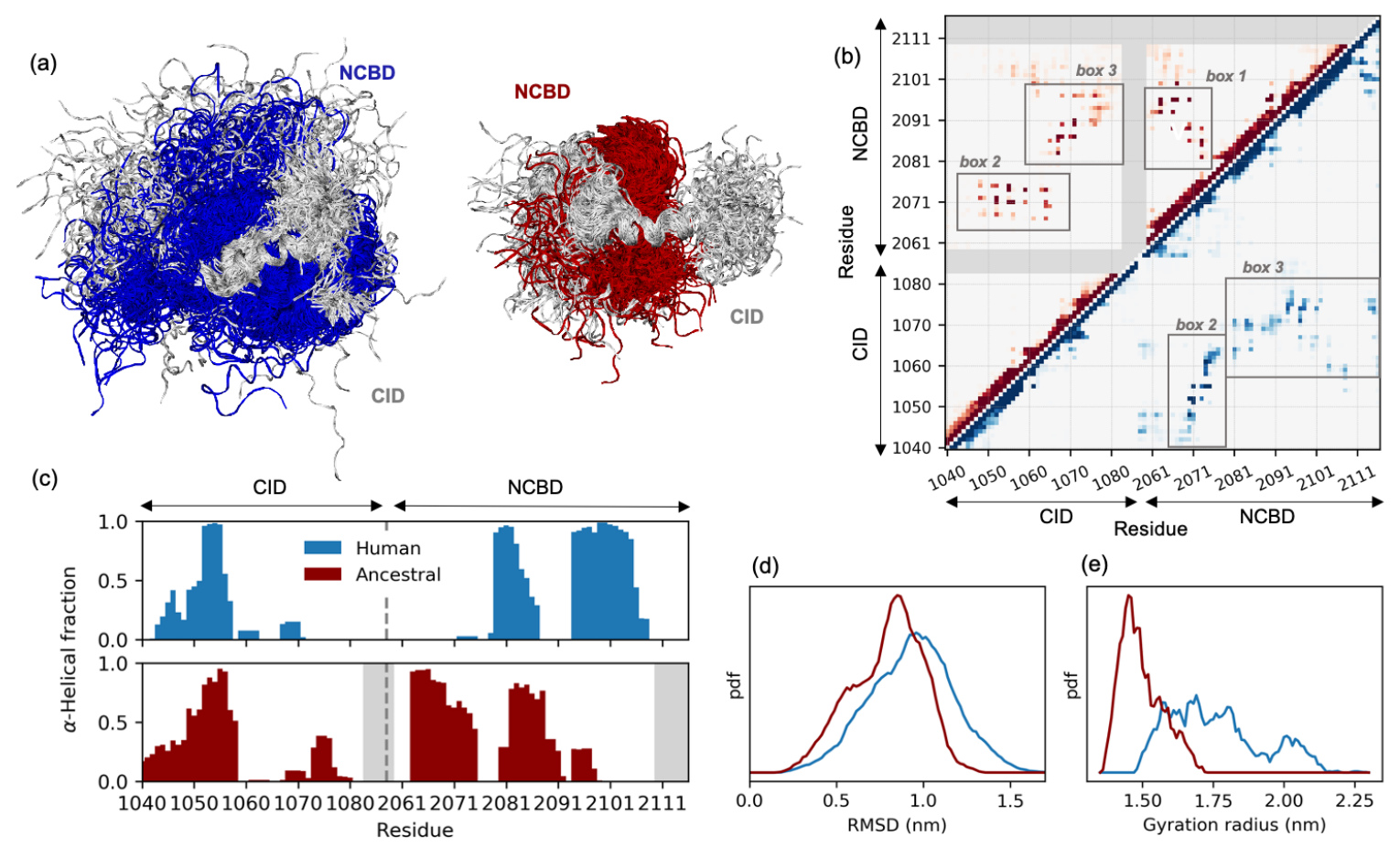

(e)

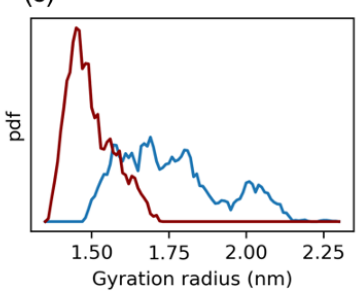

Figure 3. Comparison of the transition state of human and ancestral Cambrian-like

complexes. (a) MD-determined structural ensembles of the human (NCBD in blue and CID in light grey) and ancestral (NCBD in red and CID in light grey) TS. Both ensembles are aligned on CID helix Ca1. (b) Map representing the contact probability between each pair of residues in the human (lower right, blue) and in the ancestral (upper left, red) TS ensembles.

Probability goes from 0 (white) to 1 (dark blue/red); regions involving residues which are not present in the ancestral complex are shaded with gray. (c) Per-residue $\alpha$-helical content of the human and ancestral TS. (d, e) Probability distribution, in arbitrary units, of the root mean square deviation and of the gyration radius for the human (blue) and ancestral (red) TS ensembles. 
(a)

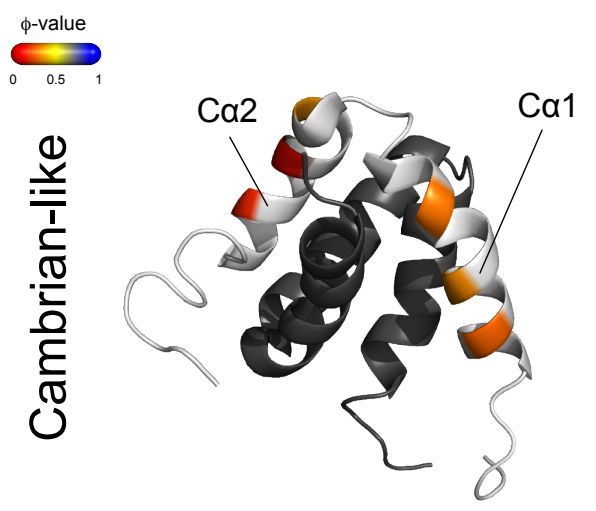

(c)

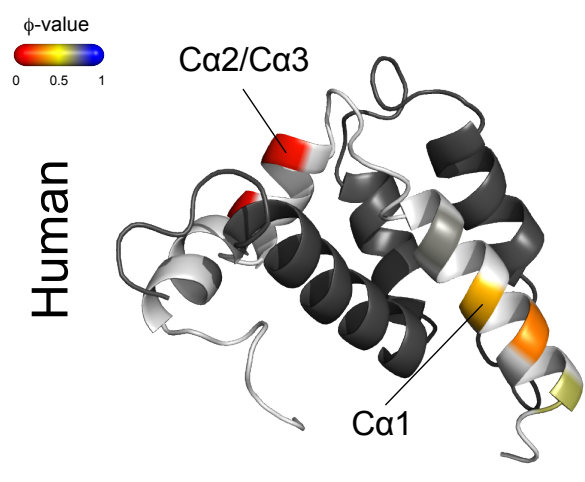

(b)

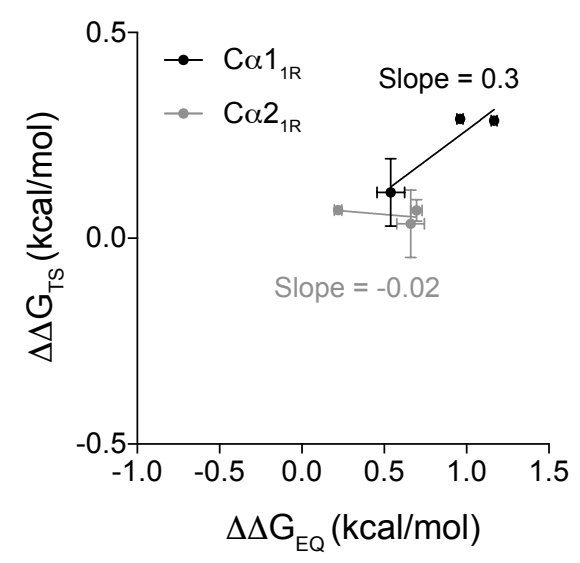

(d)

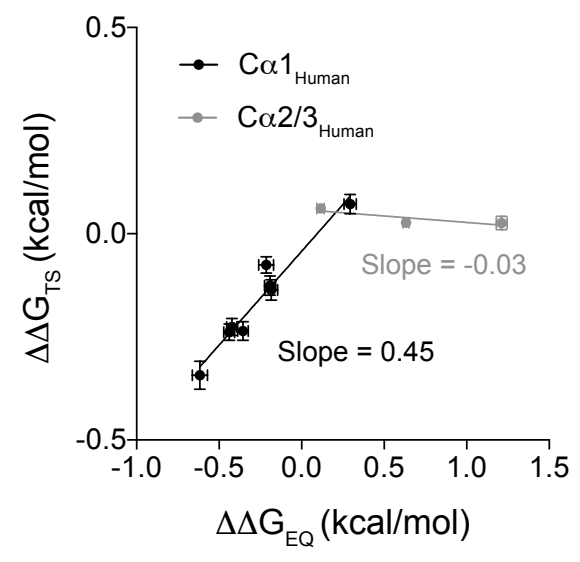

Figure 4. $\phi$-values of helix formation in CID in the Cambrian-like and human complex.

$\mathrm{Ala} \rightarrow$ Gly mutations in surface-exposed positions in the helices of $\mathrm{CID}_{\mathrm{Human}}$ and $\mathrm{CID}_{1 \mathrm{R}} \mathrm{ML}$ were introduced and the kinetic parameters for these helix-modulating mutations were obtained in stopped flow kinetic experiments. The dissociation rate constants were obtained in displacement experiments if $k_{\text {off }}$ was less than $\approx 30 \mathrm{~s}^{-1}$ or otherwise from binding experiments. Using the kinetic parameters $\left(k_{o n}\right.$ and $\left.k_{\text {off }}\right), \Delta \Delta \mathrm{G}$ in the transition state $\left(\Delta \Delta \mathrm{G}_{\mathrm{TS}}\right)$ and in the bound state $\left(\Delta \Delta \mathrm{G}_{\mathrm{EQ}}\right)$ was calculated for each mutant. The experimental conditions were 20 mM sodium phosphate $\mathrm{pH} 7.4,150 \mathrm{mM} \mathrm{NaCl}$ and the measurements were recorded at $4{ }^{\circ} \mathrm{C}$. (a) $\phi$-values for helix-modulating mutations in helix $1(\mathrm{C} \alpha 1)$ and helix $2(\mathrm{C} \alpha 2)$ of $\mathrm{CID}_{1 \mathrm{R}}{ }^{\mathrm{ML}}$ mapped onto the structure of the Cambrian-like protein complex (PDB entry 6ES5) $)^{31}$. (b) Brønsted plot for the same helix modulating mutations in $\mathrm{CID}_{1 \mathrm{R}}{ }^{\mathrm{ML}}$ in the Cambrian-like 
complex. The data were fitted with linear regression, yielding slopes of $0.3 \pm 0.1(\mathrm{C} \alpha 1)$ and $0.02 \pm 0.04(\mathrm{C} \alpha 2)$. (c) $\phi$-values for helix-modulating mutations in helix $1(\mathrm{C} \alpha 1)$ and helix 2/3 $(\mathrm{C} \alpha 2 / 3)$ of CID in the human complex mapped onto the structure of the complex (PDB entry $1 \mathrm{KBH})^{10}$. (d) Brønsted plot for helix modulating mutations in helix $1(\mathrm{C} \alpha 1)$ and helix 2/3 $(\mathrm{C} \alpha 2 / 3)$ of human CID in complex with human NCBD. Linear regression analysis yielded slopes of $0.45 \pm 0.04(\mathrm{C} \alpha 1)$ and $-0.03 \pm 0.02(\mathrm{C} \alpha 2 / 3)$. 
(a)

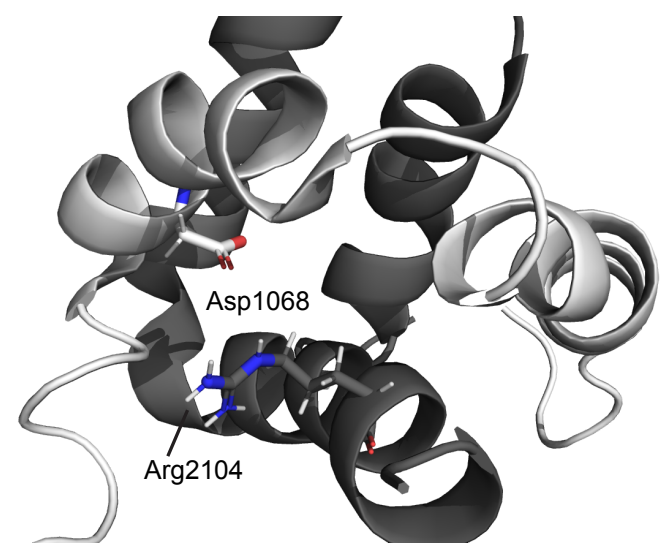

(c)
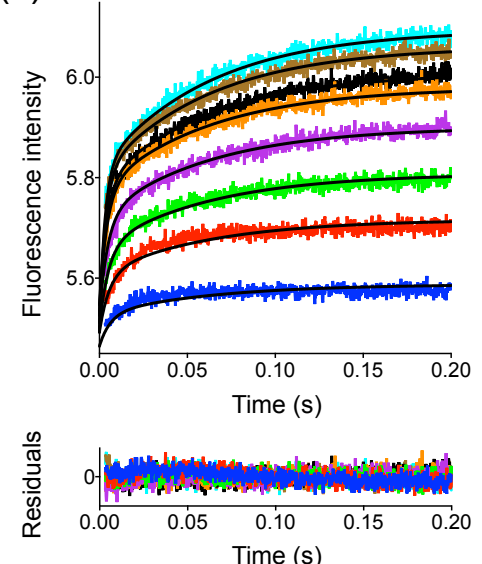

[NCBD:CID]

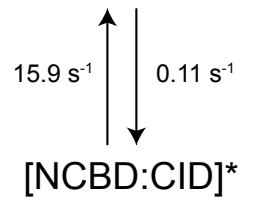

(b)

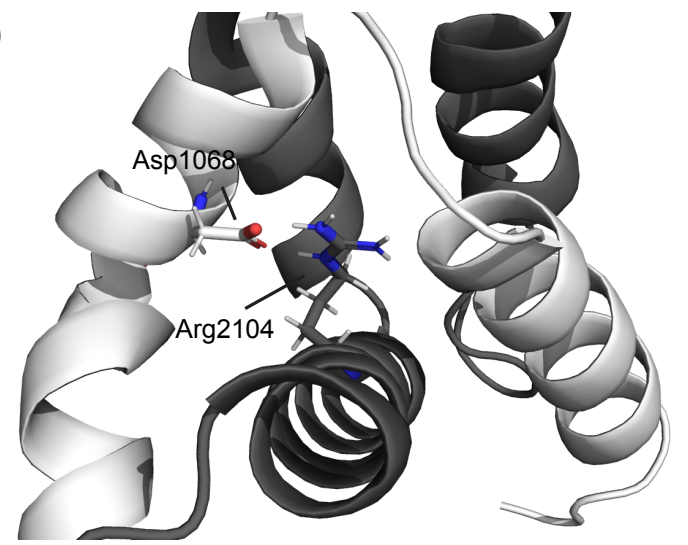

(d)
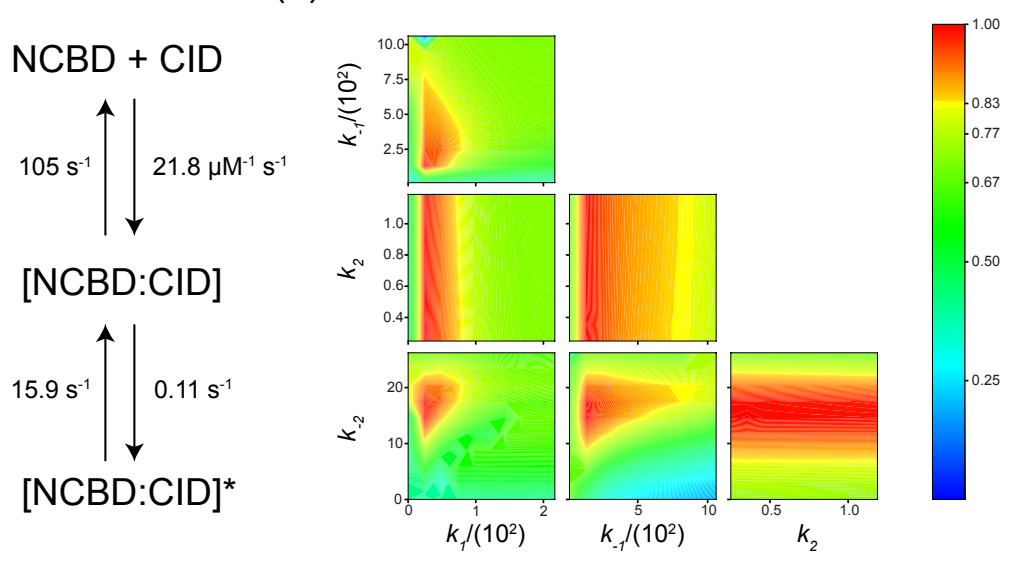

Figure 5. The conserved salt-bridge between Arg2104 in NCBD and Asp1068 in CID.

The structure of (a) the Cambrian-like (PDB entry 6ES5) ${ }^{21}$ and (b) the human NCBD/CID complex with Arg2104 and Asp1068 forming the salt-bridge highlighted as stick model.

NCBD is in dark grey and CID in light grey. (c) The stopped-flow experiment for the

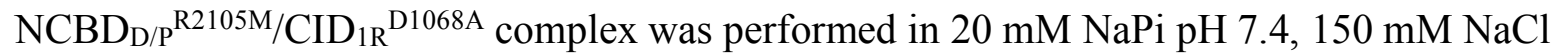
at $4^{\circ} \mathrm{C}$. The stopped flow kinetic traces were fitted globally to an induced fit model in order to obtain microscopic rate constants for each reaction step. The black solid lines represent the best fit to the kinetic traces and the residuals are shown below the curve. The best-fit microscopic rate constants obtained from global fitting to an induced fit model are shown next to the binding curves. (d) The confidence contour plot shows the variation in chi $^{2}$ as two parameters are systematically varied while the rest of the parameters are allowed to float, which can reveal patterns of co-variation between parameters in a model. The color denotes 
the $\mathrm{chi}^{2} / \mathrm{chi}^{2}$ min value according to the scale bar to the right. Here, the confidence contour plot showed that $k_{2}$ was poorly defined. The yellow boundary represents a cutoff in $\mathrm{chi}^{2} / \mathrm{chi}^{2}{ }_{\min }$ of 0.8 . 


\section{Supplementary information}

Table S1. $\phi$-values used in ancestral and human TS simulations. List of $\phi$-values used as restrains in MD simulations for the determination of the ancestral and human TS ensembles.

\begin{tabular}{|c|c|c|c|c|c|}
\hline Protein & ResID & Human Mutation & Human $\phi$-value & Ancestral Mutation & Ancestral $\phi$-value \\
\hline NCBD & 2067 & L2067A & $0.00 \pm 0.09$ & L2067A & $0.42 \pm 0.10$ \\
\hline NCBD & 2070 & L2070A & $0.20 \pm 0.04$ & L2070A & $0.45 \pm 0.14$ \\
\hline NCBD & 2074 & L2074A & $0.19 \pm 0.03$ & l & l \\
\hline NCBD & 2086 & V2086A & $0.00 \pm 0.02$ & / & / \\
\hline NCBD & 2087 & L2087A & $0.14 \pm 0.03$ & L2087A & $0.91 \pm 0.27$ \\
\hline NCBD & 2096 & L2096A & $0.16 \pm 0.03$ & L2096A & $0.81 \pm 0.52$ \\
\hline NCBD & 2099 & A2099G & $0.23 \pm 0.04$ & A2099G & $0.06 \pm 0.09$ \\
\hline NCBD & 2109 & V2109A & $0.22 \pm 0.09$ & l & l \\
\hline CID & 1043 & S1043M & $0.66 \pm 0.09$ & l & l \\
\hline CID & 1047 & $\mathrm{~A} 1047 \mathrm{G}$ & $0.24 \pm 0.05$ & $\mathrm{~A} 1047 \mathrm{G}$ & $0.21 \pm 0.16$ \\
\hline CID & 1048 & L1048A & $0.27 \pm 0.02$ & L1048A & $0.36 \pm 0.07$ \\
\hline CID & 1049 & L1049A & $0.17 \pm 0.02$ & L1049A & $0.31 \pm 0.10$ \\
\hline CID & 1050 & D1050E & $0.35 \pm 0.07$ & l & / \\
\hline CID & 1054 & T1054Q & $0.74 \pm 0.12$ & $\mathrm{~S} 1054 \mathrm{G}$ & $0.24 \pm 0.01$ \\
\hline CID & 1055 & L1055A & $0.85 \pm 0.10$ & L1055A & $0.83 \pm 0.21$ \\
\hline CID & 1056 & L1056A & $0.07 \pm 0.02$ & I & I \\
\hline CID & 1062 & I & / & M1062G & $0.31 \pm 0.06$ \\
\hline CID & 1064 & L1064A & $0.06 \pm 0.02$ & & I \\
\hline CID & 1065 & / & / & A1065G & $0.05 \pm 0.12$ \\
\hline CID & 1067 & I1067V & $0.16 \pm 0.02$ & I1067V & $0.23 \pm 0.09$ \\
\hline CID & 1071 & L1071A & $0.14 \pm 0.03$ & I & I \\
\hline CID & 1073 & I1073V & $0.15 \pm 0.05$ & / & I \\
\hline CID & 1077 & V1077A & $0.00 \pm 0.13$ & 1 & 1 \\
\hline
\end{tabular}


(a)

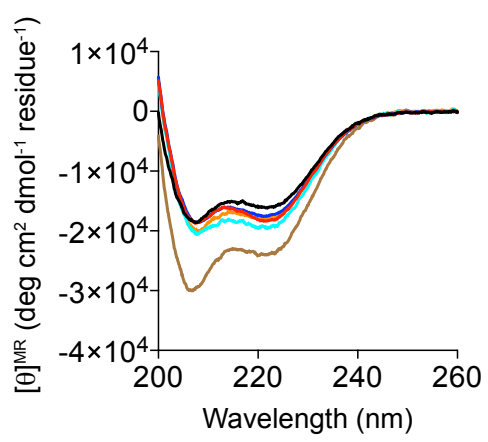

(d)

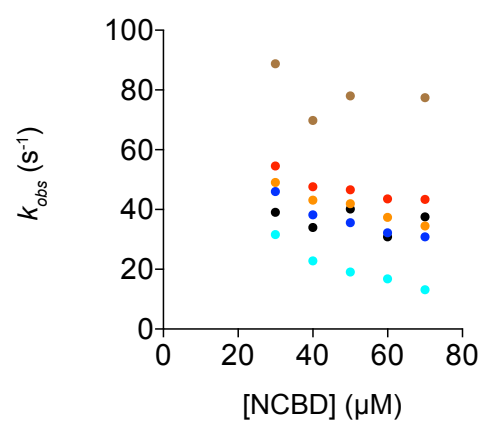

(b)

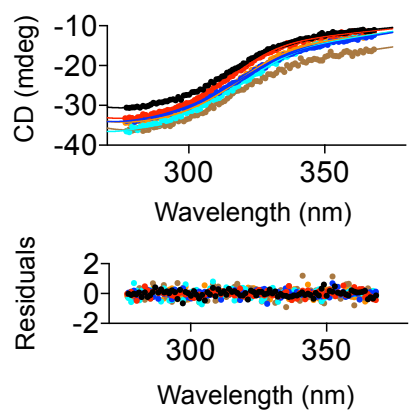

(e)

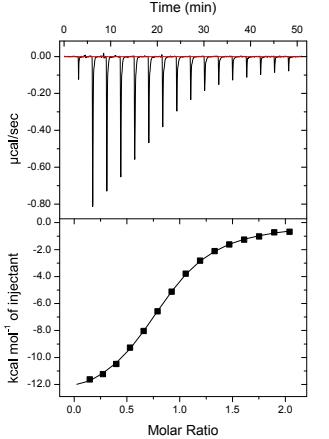

(c)

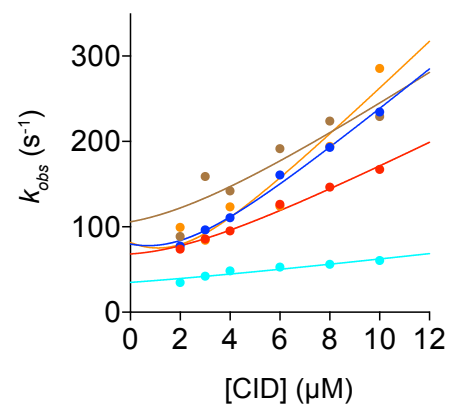

(f)

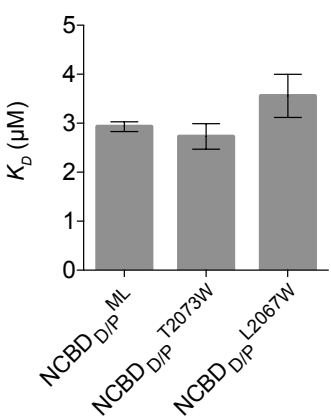

\begin{tabular}{c|c|c|c}
$\mathrm{NCBD}_{\mathrm{D} P}$ variant & $T_{M}(\mathrm{~K})$ & $k_{\text {on }}\left({\left.\mu \mathrm{M}^{-1} \mathrm{~s}^{-1}\right)}^{-1}\right.$ & $K_{D}(\mu \mathrm{M}) \mathrm{ITC}$ \\
\hline $\mathrm{ML}$ & $311 \pm 1$ & - & $2.9 \pm 0.1$ \\
\hline $\mathrm{L} 2067 \mathrm{~W}$ & $311 \pm 1$ & $14.9 \pm 0.9$ & $3.6 \pm 0.4$ \\
\hline $\mathrm{T} 2073 \mathrm{~W}$ & $314 \pm 1$ & $24 \pm 1$ & $2.7 \pm 0.3$ \\
\hline $\mathrm{S} 2078 \mathrm{~W}$ & $320 \pm 2$ & $3.5 \pm 0.7$ & - \\
\hline $\mathrm{H} 2107 \mathrm{~W}$ & $309 \pm 2$ & $19 \pm 5$ & - \\
\hline $\mathrm{Q} 2108 \mathrm{~W}$ & $313 \pm 1$ & $28 \pm 4$ & -
\end{tabular}

Figure S1. Structural, thermodynamic and kinetic properties of different $\mathrm{NCBD}_{\mathrm{D} / \mathrm{P}} \mathrm{ML}$

Trp variants. For all datasets, the color coding is the following: $\mathrm{NCBD}_{\mathrm{D} / \mathrm{P}}^{\mathrm{ML}}$ (black),

$\mathrm{NCBD}_{\mathrm{D} / \mathrm{P}}^{\mathrm{L} 2067 \mathrm{~W}}$ (red), $\mathrm{NCBD}_{\mathrm{D} / \mathrm{P}}^{\mathrm{T} 2073 \mathrm{~W}}$ (blue), $\mathrm{NCBD}_{\mathrm{D} / \mathrm{P}}^{\mathrm{S} 2078 \mathrm{~W}}$ (cyan), NCBD $\mathrm{D} / \mathrm{P}^{\mathrm{H} 2107 \mathrm{~W}}$ (brown) and $\mathrm{NCBD}_{\mathrm{D} / \mathrm{P}} \mathrm{Q}^{\mathrm{2} 108 \mathrm{~W}}$ (orange). All experiments were conducted in $20 \mathrm{mM}$ sodium phosphate $\mathrm{pH} 7.4,150 \mathrm{mM} \mathrm{NaCl}$ at $4{ }^{\circ} \mathrm{C}$ unless otherwise stated. (a) $\mathrm{CD}$ spectra for $\mathrm{NCBD}_{\mathrm{D} / \mathrm{P}^{\mathrm{ML}}}$ and the different $\mathrm{NCBD}_{\mathrm{D} / \mathrm{P}^{\mathrm{ML}}}$ Trp variants. (b) Thermal stability of different $\mathrm{NCBD}_{\mathrm{D} / \mathrm{P}^{\mathrm{ML}}}$ Trp variants in complex with $\mathrm{CID}_{1 \mathrm{R}}^{\mathrm{ML}}$. The $\mathrm{CD}$ signal at $222 \mathrm{~nm}$ was used to monitor complex dissociation and the temperature interval was $4-95^{\circ} \mathrm{C}$. The data were fitted to a two-state model (solid line, residuals in lower panel) in order to obtain estimates of the thermal denaturation midpoint of the respective NCBD/CID complex. (c) Observed rate constants 
$\left(k_{\text {obs}}\right)$ from stopped flow binding experiments for $\mathrm{NCBD}_{\mathrm{D} / \mathrm{P}^{\mathrm{ML}}} \operatorname{Trp}$ variants and $\mathrm{CID}_{1 \mathrm{R}}{ }^{\mathrm{ML}}$. The concentration of NCBD was held constant at $2 \mu \mathrm{M}$ and the concentration of CID was varied from 2-10 $\mu \mathrm{M}$. The datasets were fitted to a two-state function for bimolecular association to obtain estimates of the association rate constants $\left(k_{o n}\right)^{73}$. (d) Observed rate constants from stopped flow displacement experiments for $\mathrm{NCBD}_{\mathrm{D} / \mathrm{P}^{\mathrm{ML}}} \operatorname{Trp}$ variants and $\mathrm{NCBD}_{\mathrm{D} / \mathrm{P}^{\mathrm{ML}}}$ in complex with $\mathrm{CID}_{1 \mathrm{R}}^{\mathrm{ML}}$. The $\mathrm{NCBD}_{\mathrm{D} / \mathrm{P}^{\mathrm{ML}}}$ variant was used to displace the different $\mathrm{NCBD}_{\mathrm{D} / \mathrm{P}}{ }^{\mathrm{ML}}$ Trp variants from the protein complexes, while $\mathrm{NCBD}_{\mathrm{D} / \mathrm{P}}^{\mathrm{L} 2067 \mathrm{~W}}$ was used to displace the $\mathrm{NCBD}_{\mathrm{D} / \mathrm{P}} \mathrm{ML} / \mathrm{CID}_{1 \mathrm{R}} \mathrm{ML}^{\mathrm{ML}}$ complex. (e) An example of an ITC binding isotherm where $\mathrm{CID}_{1 \mathrm{R}}{ }^{\mathrm{ML}}$ was titrated into $\mathrm{NCBD}_{\mathrm{D} / \mathrm{P}}^{\mathrm{ML}}$. All ITC measurements were conducted in the same experimental buffer as above and at $25^{\circ} \mathrm{C}$. Fitting to a one-site two-state binding model yielded the following parameters: $K_{D}=2.9 \pm 0.1 \mu \mathrm{M}$ and $\mathrm{n}=0.8 \pm 0.007$. (f) The affinities

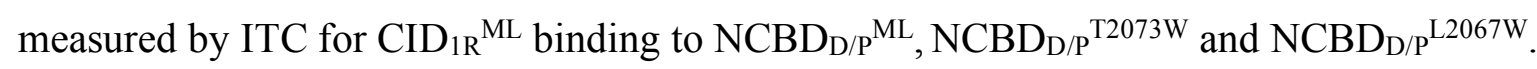
The error bars denote the standard error from the fit to a two-state function. (g) The fitted parameters for the $\mathrm{NCBD}_{\mathrm{D} / \mathrm{P}} \operatorname{Trp}$ variants and $\mathrm{NCBD}_{\mathrm{D} / \mathrm{P}} \mathrm{ML}$ from the different experiments. 
(a)

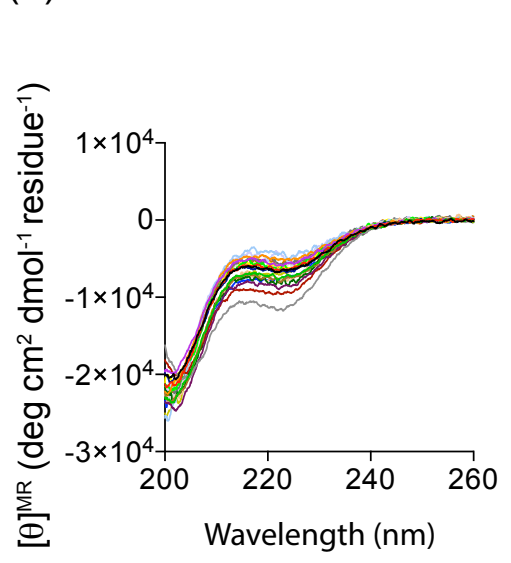

(c)

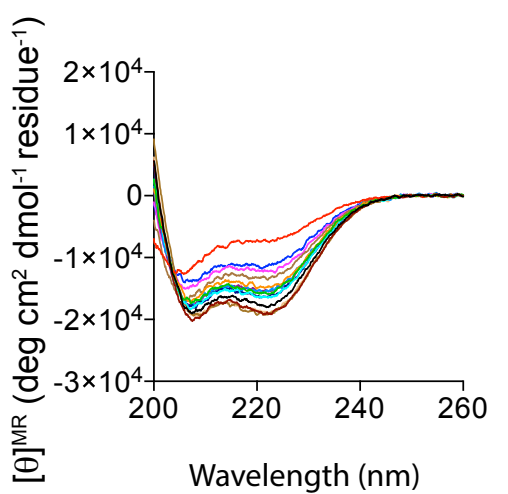

- ML

- A1047G

- L1048A

- L1049A

- D1050A

- D1050G

- D1053A

- S1054A

- S1054G

- L1055A

- L1056A

- M1062A

- M1062G

- L1064A

- A1065G

- I1067V

- I1067A

- D1068A

- R1069A

- R1069G

- L1071A

- T2073W (pWT)

- L2067A

- L2070A

- L2071A

- L2074A

- K2075M

- V2086A

- L2087A

- L2090A

- L2096A

- A2099G

- I2101A

- I2101V (b)

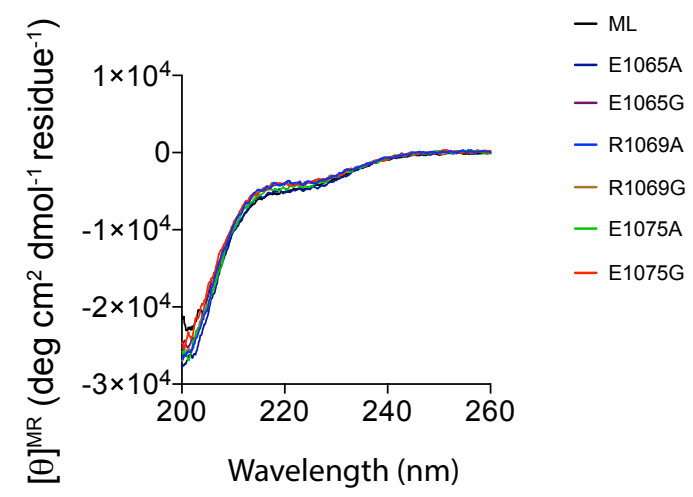

(d)

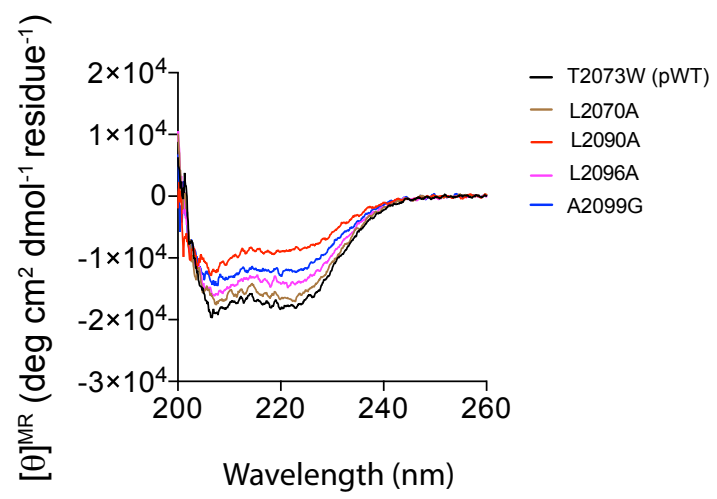

Figure S2. CD spectra of all NCBD and CID variants. All CD spectra were recorded in 20 mM sodium phosphate $\mathrm{pH} 7.4,150 \mathrm{mM} \mathrm{NaCl}$ at $4^{\circ} \mathrm{C}$ unless stated otherwise. (a) The $\mathrm{CD}$ spectra of all $\mathrm{CID}_{1 \mathrm{R}}$ variants. (b) The CD spectra for all CID Human variants. (c) The CD spectra of all NCBD $\mathrm{D} / \mathrm{P}^{\mathrm{pWT}}$ variants. (d) The $\mathrm{NCBD}_{\mathrm{D} / \mathrm{P}^{\mathrm{pWT}}}$ variants L2070A, L2090A, L2096A and A2099G displayed substantially lower helical content as compared to $\mathrm{NCBD}_{\mathrm{D} / \mathrm{P}^{\mathrm{pWT}}}$ and the CD spectra of these variants were therefore recorded in buffer supplemented with $0.7 \mathrm{M}$ TMAO. Supplementation with TMAO increased helical content of some variants. 
(a)

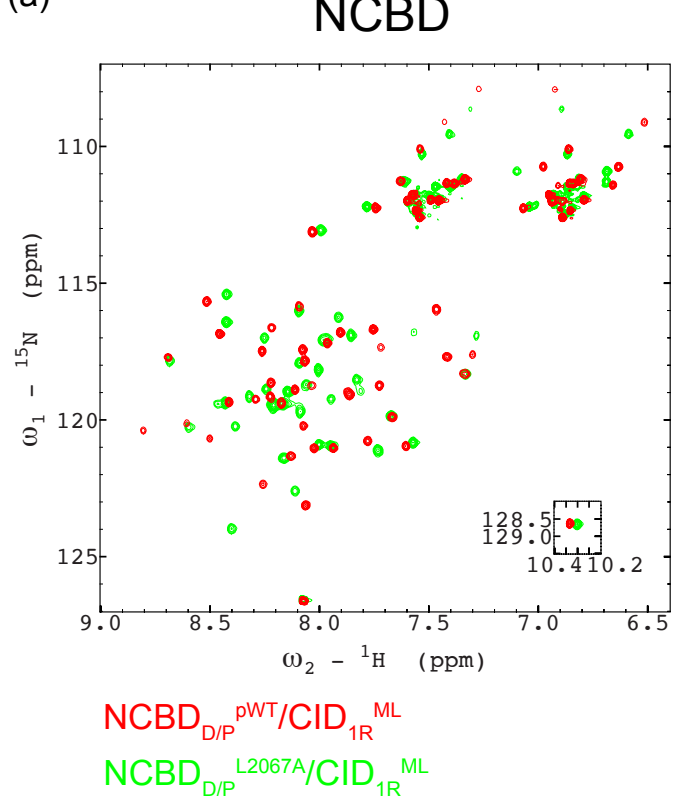

(b) $\quad$ CID

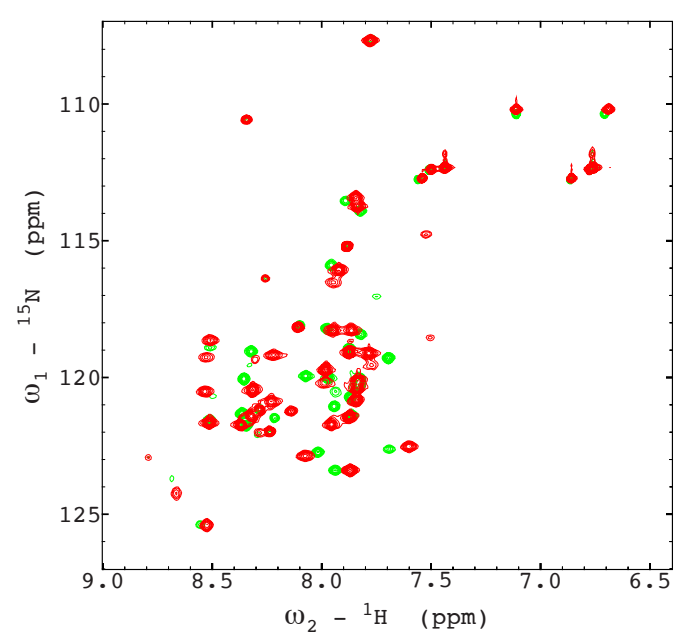

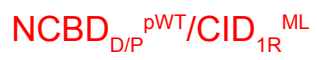

$\mathrm{NCBD}_{\mathrm{D} / \mathrm{P}^{L 2067 A} / \mathrm{CID}}{ }_{1 \mathrm{R}}^{\mathrm{ML}}$

Figure S3. ${ }^{1} \mathrm{H}-{ }^{15} \mathrm{~N}-\mathrm{HSQC}$ spectra for bound CID and NCBD domains. (a) Unlabeled $\mathrm{CID}_{1 \mathrm{R}}{ }^{\mathrm{ML}}$ bound to ${ }^{15} \mathrm{~N}$-labeled $\mathrm{NCBD}_{\mathrm{D} / \mathrm{P}^{\mathrm{pWT}}}$ (red) and ${ }^{15} \mathrm{~N}$-labeled $\mathrm{NCBD}_{\mathrm{D} / \mathrm{P}}{ }^{\mathrm{L} 2067 \mathrm{~A}}$ (green).

The inset shows the tryptophan side chain peak. (b) ${ }^{15} \mathrm{~N}$-labelled $1 \mathrm{R} \mathrm{CID}_{1 \mathrm{R}} \mathrm{ML}$ bound to unlabeled $\mathrm{NCBD}_{\mathrm{D} / \mathrm{P}}{ }^{\mathrm{pWT}}$ (red) and $\mathrm{NCBD}_{\mathrm{D} / \mathrm{P}}^{\mathrm{L} 2067 \mathrm{~A}}$ (green). 
(a)

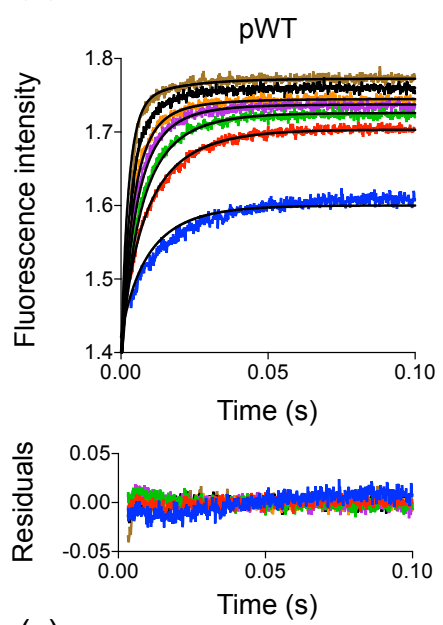

(c)
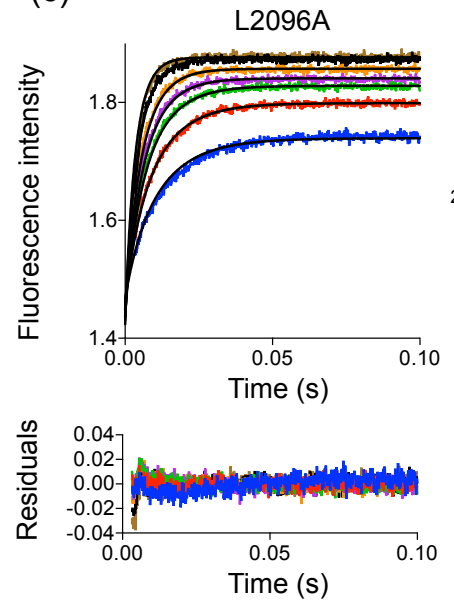

(e)

\begin{tabular}{c|c|c|c|c|c|c}
$\begin{array}{c}\mathrm{NCBD}_{\mathrm{D} / \mathrm{P}} \\
\text { variant }\end{array}$ & $\begin{array}{c}\mathrm{CID}_{1 \mathrm{R}} \\
\text { variant }\end{array}$ & Temperature $\left({ }^{\circ} \mathrm{C}\right)$ & $k_{\text {on }}\left(\mu \mathrm{M}^{-1} \mathrm{~s}^{-1}\right)$ & $K_{D}(\mu \mathrm{M}) \mathrm{ITC}$ & $\begin{array}{c}K_{D}(\mu \mathrm{M}) \\
\text { Stopped-flow }\end{array}$ & $\phi$-value \\
\hline $\mathrm{pWT}$ & $\mathrm{ML}$ & 25 & - & $0.51 \pm 0.04$ & - & - \\
\hline $\mathrm{pWT}$ & $\mathrm{ML}$ & 20 & - & $0.25 \pm 0.04$ & - & - \\
\hline $\mathrm{pWT}$ & $\mathrm{ML}$ & 15 & - & $0.14 \pm 0.03$ & - & - \\
\hline $\mathrm{pWT}$ & $\mathrm{ML}$ & 10 & - & $0.35 \pm 0.25$ & - & - \\
\hline $\mathrm{pWT}$ & $\mathrm{ML}$ & 4 (extrapolated) & $56.2 \pm 0.7$ & $0.36 \pm 0.11$ & - & - \\
\hline $\mathrm{L} 2070 \mathrm{~A}$ & $\mathrm{ML}$ & 4 & $24.6 \pm 0.6$ & - & $2.3 \pm 0.1$ & $0.45 \pm 0.14$ \\
\hline $\mathrm{L} 2096 \mathrm{~A}$ & $\mathrm{ML}$ & 4 & $27.9 \pm 0.1$ & - & $0.85 \pm 0.01$ & $0.8 \pm 0.5$ \\
\hline $\mathrm{A} 2099 \mathrm{G}$ & $\mathrm{ML}$ & 25 & - & $5 \pm 1$ & - & - \\
\hline $\mathrm{A} 2099 \mathrm{G}$ & $\mathrm{ML}$ & 4 & $48 \pm 1$ & - & - & $0.06 \pm 0.02$
\end{tabular}

(b)
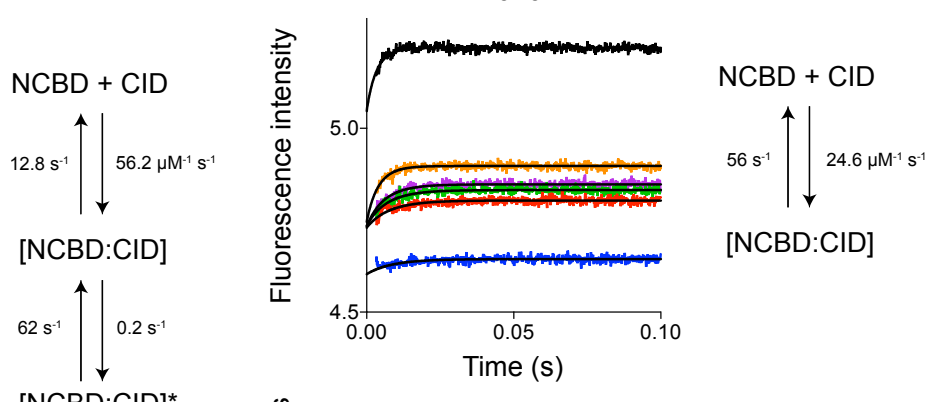

[NCBD:CID]
$\mathrm{NCBD}+\mathrm{CID}$ (d)
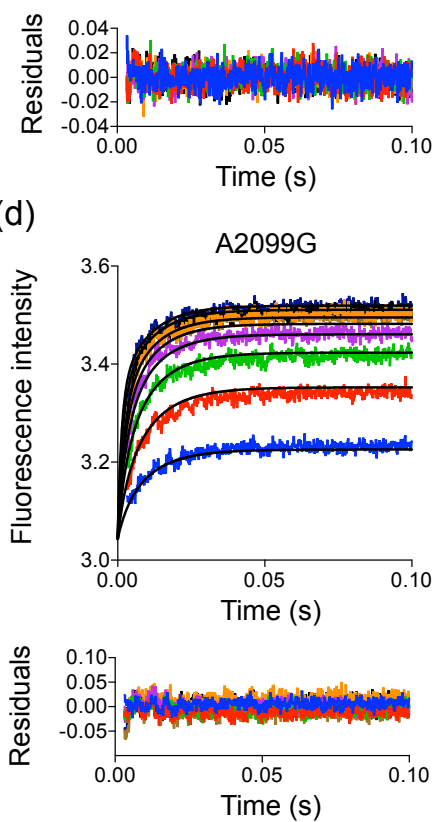

$\mathrm{NCBD}+\mathrm{CID}$

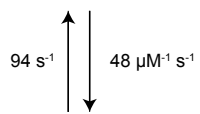

[NCBD:CID]

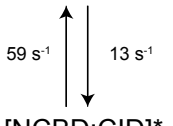

[NCBD:CID]*

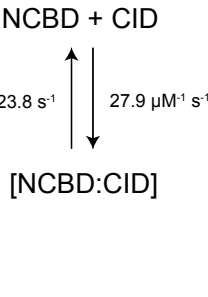

[NBD:CID]*

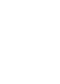


constants. (b) The binding kinetics of $\mathrm{NCBD}_{\mathrm{D} / \mathrm{P}}^{\mathrm{L} 2070 \mathrm{~A}}$ and $\mathrm{CID}_{1 \mathrm{R}}^{\mathrm{ML}}$ was monophasic and was globally fitted to a two-state binding mechanism. (c) The binding kinetics of $\mathrm{NCBD}_{\mathrm{D} / \mathrm{P}} \mathrm{L}^{2096 \mathrm{~A}}$ and $\mathrm{CID}_{1 \mathrm{R}}^{\mathrm{ML}}$ was monophasic and the figure shows the fit to a two-state binding model. (d)

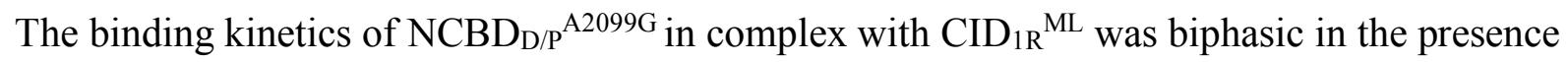
of 0.7 M TMAO and was fitted to an induced fit model. (e) A table with kinetic and thermodynamic parameters obtained in stopped-flow and isothermal titration calorimetry (ITC) experiments for the protein complexes. The errors are Standard Errors from fitting a two-state model for binding. The error of the extrapolated affinity at $4{ }^{\circ} \mathrm{C}$ for the $\mathrm{NCBD}_{\mathrm{D} / \mathrm{P}^{\mathrm{pWT}}}$ was estimated to be $30 \%$. 


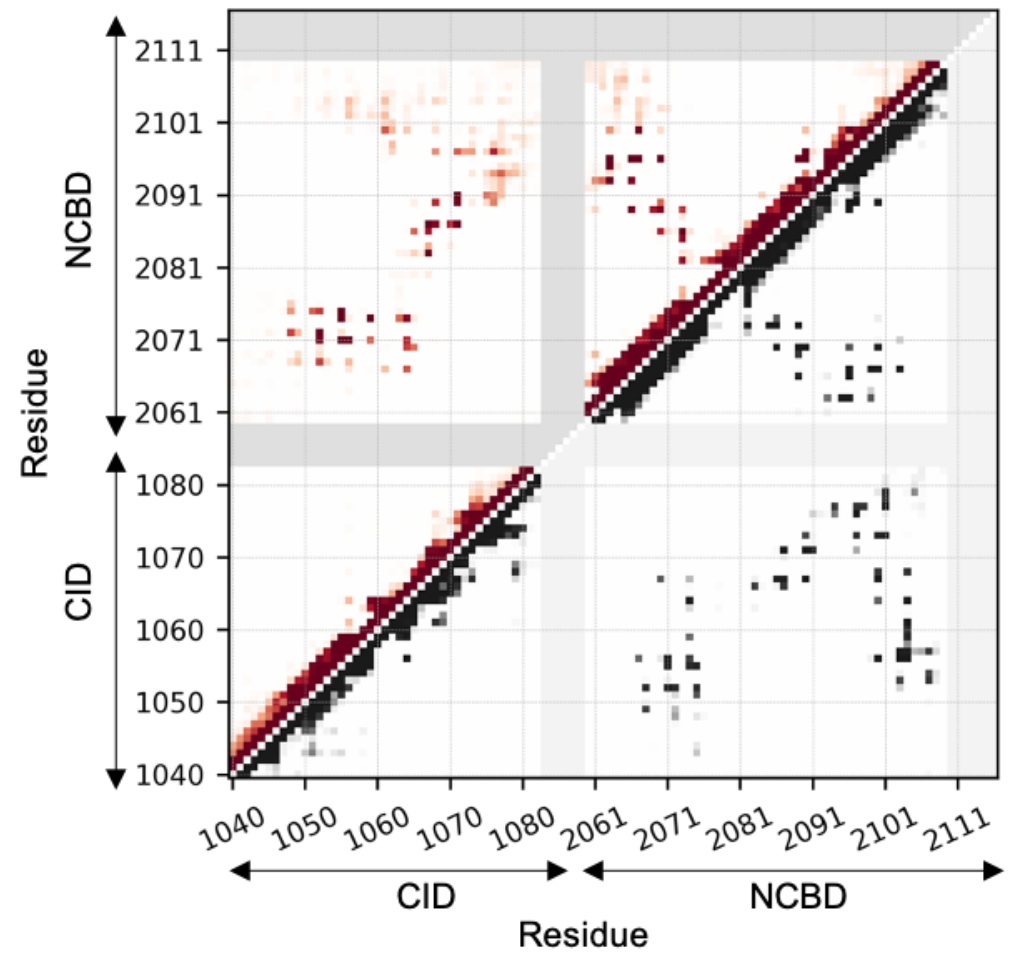

Figure S5. Map representing the contact probability between each pairs of residues in the ancestral native state (lower right, gray) and in the ancestral TS (upper left, red) ensembles. Probability goes from 0 (white) to 1 (dark gray/red); regions, involving residues which are present in the human but not the ancestral complex, are shaded with gray to be consistent with Figure 3 in the main text. 


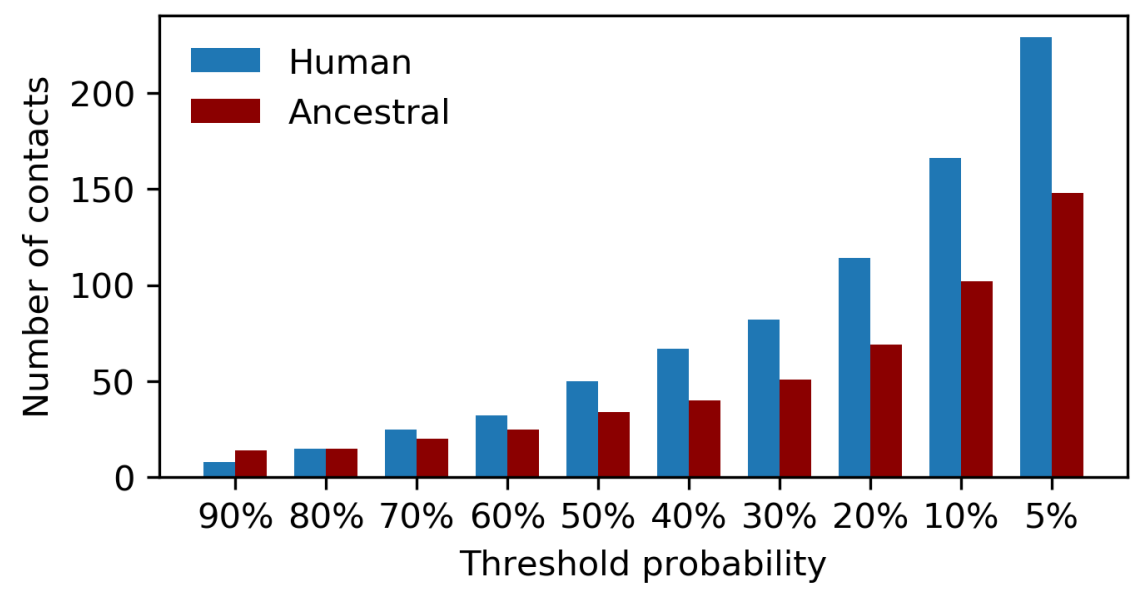

Figure S6. Number of intermolecular residue-residue contacts present in the human/ancestral

TS ensemble with a probability higher than a threshold probability. 